NBER WORKING PAPER SERIES

\title{
INTER-BRAND COMPETITION IN THE CONVENIENCE STORE INDUSTRY, STORE ACCESSIBILITY AND HEALTHCARE UTILIZATION
}

\author{
Hung-Hao Chang \\ Chad D. Meyerhoefer \\ Working Paper 24628 \\ http://www.nber.org/papers/w24628 \\ NATIONAL BUREAU OF ECONOMIC RESEARCH \\ 1050 Massachusetts Avenue \\ Cambridge, MA 02138 \\ May 2018
}

Senior authorship is equally shared. The authors would like to thank the National Health Institute in Taiwan and Taiwan Fair Trade Commission for providing the convenience store data and National Health Institute in Taiwan for providing access to the individual health claim data. Early versions of this paper were presented at the Ohio State University, University of Tampa, Temple University, the International Health Economics Association meeting, and the Agricultural and Applied Economics Association meeting. Valuable comments from the participants of these seminars and meetings are appreciated. In addition, we would like to thank Daisy Dai for providing feedback on the final draft of the paper. The views expressed herein are those of the authors and do not reflect the policies of National Health Institute in Taiwan and Taiwan Fair Trade Commission. The authors are responsible for any remaining errors. The views expressed herein are those of the authors and do not necessarily reflect the views of the National Bureau of Economic Research.

NBER working papers are circulated for discussion and comment purposes. They have not been peer-reviewed or been subject to the review by the NBER Board of Directors that accompanies official NBER publications.

(C) 2018 by Hung-Hao Chang and Chad D. Meyerhoefer. All rights reserved. Short sections of text, not to exceed two paragraphs, may be quoted without explicit permission provided that full credit, including $\odot$ notice, is given to the source. 
Inter-brand Competition in the Convenience Store Industry, Store Accessibility and Healthcare Utilization

Hung-Hao Chang and Chad D. Meyerhoefer

NBER Working Paper No. 24628

May 2018

JEL No. H51,I12,L81

\title{
ABSTRACT
}

We investigate the impact of access to convenience stores and competition between convenience store chains on medical care use and expenditures in Taiwan; the country with the highest density of convenience stores in the world. Our study makes use of insurance claims from 0.85 million individuals enrolled in Taiwan's national health insurance program from 2002-2012 and administrative data on convenience store chain sales. While we find that both greater store accessibility and higher levels of inter-brand competition reduce the use and cost of outpatient medical services and prescription drugs, healthcare utilization is more responsive to changes in competition. Since convenience stores in Taiwan are typically the healthier option for ready-toeat food, we postulate that the decline in medical care utilization is driven by a reduction in convenience store prices and increase in service quality relative to other food outlets. This is supported by findings from survey data indicating that convenience store competition is associated with greater consumption of more healthy foods, lower consumption of less healthy foods, and decreases in obesity rates. While the effects we find are precisely estimated, they are small in magnitude, with the increase in convenience store competition experienced by Taiwan over a 10-year period reducing medical expenditures on outpatient services and on prescription drugs by around one half of one percent.

\author{
Hung-Hao Chang \\ Department of Agricultural Economics \\ National Taiwan University \\ No 1, Roosevelt Rd, Sec 4 \\ Taipei 10617 \\ Taiwan \\ hunghaochang@ntu.edu.tw \\ Chad D. Meyerhoefer \\ Rauch Business Center \\ Lehigh University \\ 621 Taylor Street \\ Bethlehem, PA 18015 \\ and NBER \\ chm308@lehigh.edu
}

A data appendix is available at http://www.nber.org/data-appendix/w24628 


\section{Introduction}

As rates of obesity and chronic disease have increased worldwide, the associated medical care costs have strained national budgets and individual finances. In the United States the annual medical care costs of obesity rose from $\$ 225.1$ billion in 2005 to $\$ 342.2$ billion in 2013 (both in 2013 dollars; Cawley and Meyerhoefer 2012; Biener, Cawley and Meyerhoefer 2017). Most of these costs are due to the treatment of chronic diseases that are either caused by or exacerbated by obesity (Thorpe and Philyaw 2012). Other countries have experienced similar cost increases, with projections of the cumulative global burden caused by chronic disease reaching $\$ 47$ trillion over a twenty year period (Bloom et al. 2011).

Among the many factors linked to obesity and chronic disease, a recent line of research suggests that the structure of retail food markets contributes to poor nutrition and rising rates of obesity. Studies of U.S. markets focus on residents' proximity to supermarkets, which are more likely to offer fruits, vegetables and other healthy foods, and their proximity to convenience stores or fast food restaurants, which sell mostly calorie dense and pre-prepared foods. Findings suggest that the presence of supermarkets in one's neighborhood is negatively correlated with body mass index (BMI) and obesity, and the presence of convenience stores is positively correlated with BMI and obesity for both adults and adolescents (Morland, Roux and Wing 2006; Galvez et al. 2009; Powell et al. 2007; Marlow, 2015). Likewise, children who reside in areas without supermarkets are more likely to be obese (Thomsen et al. 2016; Schafft, Jensen and Hinrichs 2009), as are those who attend school near fast food restaurants (Currie et al. 2010; Davis and Carpenter 2009). The correlation between poor supermarket access and obesity is consistent with research finding that residents who live far away from supermarkets pay higher prices for food, have limited access to healthy foods, and consume fewer fruits and vegetables (Blanchard and Matthews 2007; Blanchard and Lyson 2002; Morland, Wing and Roux 2002, Laraia et al. 2004).

Despite evidence of a link between food outlet availability and obesity, the effects of food outlet competition on obesity and chronic disease have not been explored, nor have the implications of either market characteristic for medical care costs. There are several reasons why food outlet competition could affect health and medical expenditures. First, competition typically lowers prices (Hausman and Leibtag 2007), and decreases in the relative price of healthy (unhealthy) foods may lower (raise) the incidence and severity of chronic disease and body weight (Meyerhoefer and Leibtag 2010; Chou, Grossman and Saffer 2004; Powell 2009, Schroeter, Lusk and Tyner 2008). ${ }^{1}$ Second, competition also compels food outlets to raise product quality (Matsa 2011), which in the case of supermarkets, could cause the

\footnotetext{
${ }^{1}$ In the model constructed by Schroeter, Lusk and Tyner (2008) it is possible, under certain conditions, for a price reduction in a low-calorie food to actually increase body weight. This could occur if the responsiveness of body weight to changes in the consumption of high-calorie and low-calorie food is very similar and the crossprice elasticity of high-calorie food with respect to the price of low-calorie food is greater than the own-price elasticity of low-calorie food.
} 
substitution of more healthy food for less healthy food. Reductions in rates of obesity and chronic disease through either of these mechanisms will reduce expenditures on medical care (Cawley and Meyerhoefer 2012; Cawley et al. 2015; Meyerhoefer and Leibtag 2010).

We extend previous research on the connection between retail food market structure and health by investigating whether greater food outlet density and higher levels of competition impact the use and cost of medical services. In order to empirically identify these relationships we analyze unique data on the convenience store industry in Taiwan from 20022012. These data are linked to health care claims from Taiwan's national health insurance program. Unlike similarly named stores in the United States or Western Europe, convenience stores in Taiwan sell relatively healthy food and provide more nutrition information than their competitors in the market for food away from home. Convenience stores account for just over half of all retail food outlets in Taiwan, and sales contracts with manufacturers make it easy to determine which products can be sold at different prices across convenience store chains (Taiwan Fair Trade Commission [TFTC] 2016). As a result, the convenience store industry in Taiwan is an excellent case study of the effects of inter-brand competition (i.e. competition between convenience store chains, but not between stores within the same chain) on health.

Consistent with expectations, we find that greater convenience store density and more inter-brand competition among convenience store chains lowers medical care use and expenditures. We hypothesize that this is due to lower prices and improvements in food and service quality at convenience stores relative to Chinese restaurants, breakfast and lunch shops, night markets and traditional markets that also offer ready-to-eat food. In support of our hypothesis we conduct an additional analysis using survey data and find that greater store density and market competition is associated with an increase in the consumption of more healthy foods, and a decrease in the consumption of less healthy foods. Moreover, rates of obesity are lower among residents living in areas with more intense inter-brand competition and more convenience stores per capita.

While the effects we find are precisely estimated, they are small in magnitude. For example, a change in market structure resulting in a 1,000 unit reduction in the HerfindahlHirschman index $(\mathrm{HHI})^{2}$ lowers expenditures on outpatient care by only $0.31 \%$ and expenditures on prescription drugs by $0.36 \%$. This is consistent with recent studies that suggest differences in demand rather than food availability and food prices are the primary determinant of socioeconomic disparities in nutrient consumption (Allcott, Diamond and Dube 2017; Handbury, Rahkovsky and Schnell 2016). Our findings therefore suggest that

2 The index is $H H I=\sum_{i=1}^{4} s_{i}^{2} \cdot 10,000$, where $s_{i}$ is the market share of each convenience store chain in each town. The HHI is widely used to measure market concentration. For example, the U.S. Department of Justice uses HHI as a screening device for regulatory oversight of mergers. Their 2010 horizontal merger guidelines define unconcentrated, moderately concentrated, and highly concentrated markets as those with $\mathrm{HHI}<1,500$; 2,500 $>\mathrm{HHI}>=1,500 ; \mathrm{HHI}>=2,500$, respectively (USDOJ 2010). 
pro-competitive policies applied to venders of healthy food can have small positive externalities through modest reductions in healthcare costs. By implication, policies that promote the consumption of healthy foods will be most effective if they do not limit competition between food outlets specializing in the sale of such foods.

The results of this paper are relevant to several strands of the literature. First, we make a contribution to the growing literature on the role of food outlets in health determination. Previous studies consider only the impact of food outlet accessibility on health outcomes, without taking into account the level of competitive between outlets (e.g., Morland, Roux and Wing 2006; Galvez et al. 2009; Powell et al. 2007; Marlow 2015). This may result in inconsistent findings because accessibility and competition need not be positively correlated across all geographic locations, making it difficult to determine the bias caused by the failure to account for competition. ${ }^{3}$ We incorporate measures of both food outlet accessibility and competition in our models, and find that inter-brand competition is a stronger determinant of medical care costs than food outlet accessibility as measured by the per capita number of convenience stores. We also provide evidence of the mechanisms responsible for these effects, which has been lacking in previous studies.

This paper also makes a contribution to the literature on the determinants of medical care utilization and costs. While prior studies have considered how access to and competition among medical facilities affects medical care use (e.g., Gaynor and Town 2011), this is the first study that we are aware of to consider the impact of food outlet density and competition on medical care costs. A final contribution of our study is the use of rich, administrative data on both convenience store location and sales and on medical care costs and utilization. This is particularly important for reducing the potential for measurement error to bias the estimates.

\section{The Convenience Store Industry in Taiwan}

Taiwan has had the highest density of convenience stores in the world since 2003 (Chiu 2006; Hsu and Huang 2006). In 2017, total sales in the convenience store industry were NT\$ 185 million, and now exceed NT\$ 300 million (Taiwan Ministry of Finance [TMF] 2017). The four major convenience store chains in Taiwan, which include 7-Eleven, FamilyMart, HiLife, and OK-Mart, account for 98\% of convenience store outlets. At the end of 2013 these four chains grew to 10,188 total outlets, or one store for every 2,305 people. On average, there is also one store in every 3.6 square kilometers of land (Taiwan Today 2014). 7-Eleven is the longest standing convenience store franchise in Taiwan. It was established in 1979 and currently accounts for $49 \%$ of the total number of outlets. FamilyMart, Hi-Life, and OK-Mart were all established in 1988 and account for 29\%, 13\% and 9\% of total outlets, respectively

\footnotetext{
${ }^{3}$ For example, it isn't clear whether the sum of pecuniary and non-pecuniary costs of food is greater for a household that lives close to a supermarket that faces no competition, or a household that lives far from a supermarket that faces significant competition.
} 
(Chang and Dawson 2007; Taiwan Fair Trade Commission [TFTC] 2016).

Chain convenience stores in Taiwan follow a mandated franchise system, whereby the parent company of each chain (the franchisor) sells store outlet owners (franchisees) the right to use intellectual property in return for a payment or royalty fee based on sales at the outlet. The parent company provides managerial assistance to franchisees, who must comply with franchise regulations covering product mix, the arrangement and display of products, and product prices. In order to avoid inter-brand competition among different outlets in the same franchise, the parent company mandates a uniform price for all products. The one exception is when an outlet faces new competition from another chain, in which case the outlet is permitted to use promotional pricing (e.g. buy one get one free offers) to defend its market share (Huarng and Yu 2014; Taiwan Chain Stores and Franchise Association 2015). The parent company also advises outlets to decorate their stores and display products in a similar way to limit inter-brand competition, maintain consistency in chain attributes, and meet quality standards. As a result of these regulations, competition in price and store quality can only occur between outlets in different convenience store chains, although an outlet can differentiate itself from all others based on service quality.

The types of food products sold at convenience stores have changed over time. During the first ten to fifteen years of the convenience store industry, stores offered mainly snack food for grab-and-go customers, cigarettes and alcoholic beverages. Most of the products were national brands with prices determined by manufacturers, precluding price competition between different stores and chains. Approximately twenty years after the first convenience stores were established, chains began to develop private label products. Meal boxes, deserts and non-alcoholic drinks make up a large proportion of private label products (Hung 2005). In response to an increase in the demand for healthy foods, convenience store chains began to place comprehensive nutrition labels on private label products and market their quality and health benefits ${ }^{4}$. In contrast to national brand foods, chain companies control the production and supply chain for private label products and have exclusive control over price. After the introduction of private label products, convenience stores also began to provide dining facilities allowing purchases to be eaten on-site.

The introduction of private label products fundamentally changed inter-brand competition between convenience store chains as well as competition between convenience stores and other types of food outlets. Private label products led to intense price competition between chains and product differentiation based on food and beverage quality, while the accompanying addition of dining facilities added yet another dimension to inter-brand competition. The expansion of private label food and beverage offerings at convenience

\footnotetext{
${ }^{4}$ For example, the largest convenience store chain, 7-Eleven, began to sell private label meal boxes in 2001, and private label freshly brewed coffee in 2004. Both products contained nutritional information and promotional health claims on their labels.
} 
stores also put them in competition with supermarkets and beverage outlets. However, the largest new competitive front was with Chinese restaurants, food vendors, and meal shops, which lost customers to convenience stores with dining facilities (Cheng et al. 2009).

Driven by the success of private label products, the number of convenience stores grew 178\% between 1999 and 2016, while the number of restaurants grew by only 66\%, beverage outlets grew by $55 \%$ and other food outlets grew by $28 \%$ over the same time period (TFTC 2016). In terms of total sale values, the convenience store sector grew $19.8 \%$ between 2013 and 2016, while there was negative growth among breakfast and lunch shops and food vendors of $-7.6 \%$ and $-8.1 \%$, respectively (TMF 2017). This rapid growth of convenience stores over the past eighteen years has made them the largest category of food service provider in Taiwan, accounting for 53\% of all food outlets. The three next largest providers, Chinese restaurants, meal shops and traditional markets now account for only $30 \%$ of total food outlets, combined (TFTC 2016).

The composition of convenience store sales reflects their current role as a provider of ready-to-eat foods in addition to their traditional role as provider of alcohol and tobacco products. Twenty five percent of convenience stores sales are for ready-to-eat items such as meal boxes and sandwiches, and $24 \%$ of sales are for non-alcoholic drinks, while $28 \%$ of sales are for cigarettes and 6\% are for alcoholic drinks (TFTC 2016). Among ready-to-eat food, private labels account for $75 \%$ of sales, and national products account for only $25 \%$ of sales. In contrast, the percentage of private label non-alcoholic drink sales is only $29 \%$. Notably, all alcohol and tobacco products are national brands sold at the same price by all convenience store chains. Therefore, inter-brand competition between convenience store chains is largely through ready-to-eat food sales, and to a lesser extent, the sale of nonalcoholic drinks. It is notable that private label products in these categories are also relatively healthy. In particular, the best-selling individual products at convenience stores are soy milk, rice milk, salad, alkaline water, and tea egg, while meal boxes are among the best-selling ready-to-eat products (TFTC 2016).

Overall, the provision of healthier food options at convenience stores suggests that reductions in price and increases in product quality through inter-brand competition between convenience store chains could result in an improvement in the healthfulness of diets. This is in no small part due to the fact that price competition for private label products reduces the price of ready-to-eat food at convenience stories relative to food at Chinese restaurants, traditional markets and meal shops, all of which primarily sell calorie-dense food.

\section{Administrative Data}

Our empirical analysis of the impact of convenience store accessibility and inter-brand competition on medical expenditures draws on four administrative population-based datasets. A secondary analysis of the mechanisms underlying our primary findings is based on 
household survey data. The characteristics of the administrative databases and the variables we derive from each data source are described below.

\subsection{Health claim profiles from the National Health Insurance Program}

Information on medical care use and expenditures is drawn from the administrative health claim profiles of a sub-set of individuals enrolled in Taiwan's national health insurance program (NHI; Chiang 1997; Wu et al. 2010). The NHI was instituted in 1995 and now covers $98 \%$ of the residents in Taiwan. We used a 5\% random sub-sample of NHI enrollees in 2005 (one million individuals) provided by the National Health Institute in Taiwan. ${ }^{5}$ We then further excluded individuals who were not continuously enrolled between 2002 and 2012. The health claim profiles contain the number of visits and total expenditures for outpatient and inpatient services as well as the number of prescription fills and prescription drug expenditures. Our primary outcome variables are binary indicators for any outpatient, any inpatient, and any prescription fills during the year and total annual medical expenditures in 2012 new Taiwan dollars (NT\$) from all sources for these three medical services. The sources of expenditures include third-party payments from the NHI and out-of-pocket payments from individuals.

We construct several control variables from the health claim profiles. These include binary indicators for gender and four employment categories corresponding to different versions of the NHI program (labor insurance for general hired or self-employed workers, government employee insurance, farmer insurance and other social insurance programs for non-employed enrollees or soldiers) ${ }^{6}$, and 325 indicators for township of residence (i.e. township fixed effects). ${ }^{7}$ In addition, we extract the age of each NHI enrollee and the monthly earned income of the insurant, which we covert to 2012 NT\$. ${ }^{8}$ Non-working spouses and children are also assigned the monthly earned income of the insurant.

\subsection{Convenience Store Competition Databank}

Our second dataset is the Convenience Store Competition Databank, which contains administrative profiles of the top four major chain convenience stores. The Taiwan Fair Trade Commission (TFTC) has maintained this database since 2000. In addition to the exact

\footnotetext{
${ }^{5}$ When drawing the $5 \%$ sub-sample of NHI enrollees, the Institute considered the distribution of population age and gender in each county. As a result, the sub-sample is nationally representative of the population of NHI enrollees in 2005.

${ }^{6}$ These four main insurance programs differ in insurance premiums and contribution rates. For instance, Farmers Health Insurance participants pay 30\% of health insurance premiums levied at $2.55 \%$ of total benefits, whereas government employees and private sector employees pay $40 \%$ of premiums levied at $7.15 \%$ of total benefits, and $30 \%$ of premiums levied at $5.5 \%$ of total benefits, respectively (Chiang 1997). We define the occupation of the NHI insurants based on their specific type of NHI social insurance.

${ }^{7}$ In the NHI, dependents are assigned the same insurance category as the primary wage earner.

${ }^{8}$ Lien (2011) compares the level of earned income reported in the NHI profile to actual wage income reported in other data sources. He finds that earned income from the NHI profile is equal to $90 \%$ of actual wage income reported elsewhere.
} 
location of each individual outlet, the database contains the sales of each outlet from tax profiles created by the Ministry of Finance. We construct two variables from these data. The first is the total number of convenience store outlets (from the top four chains) in each township divided by the township population. This is our measure of food accessibility. The second variable is the Herfindahl-Hirschman index (HHI), which is calculated across the four major convenience store chains in each township. The HHI is defined as the sum of the squared market shares of each of the four convenience store chains multiplied by 10,000. We use this conventional version of the HHI when reporting descriptive statistics, but normalize the index to between 0 and 1 in our empirical models. Market shares are determined by adding the annual sales of all individual store outlets in the same chain in every township and dividing this number by the annual sales of all outlets in the township. As a result, the HHI captures inter-brand competition between the four major convenience store chains at the township level. HHI values of 0 indicate perfect competition, while index values of 10,000 (or 1 in the normalized version) indicate monopoly.

Because the prices of all products are generally standardized across outlets in the same chain, as are store formats and advertising, we do not include a measure of intra-brand competition in our models. Both convenience store outlets per capita and the HHI for 20022012 are merged to the NHI health claim profiles using township geocodes. There are 358 townships in Taiwan, but 33 townships contain no convenience stores, so our estimation sample is based on the 325 townships with at least one convenience store between 2002 and 2012. The final estimation sample contains 9,353,987 person-year observations, with approximately 0.85 million individuals in each year.

\subsection{Local healthcare resources}

Our third set of data is drawn from the Taiwanese Ministry of Health and Welfare and contains information on the supply of healthcare providers across the country. We construct three measures of provider supply at the township-level from 2002-2012 and merge these to the NHI claim profiles using township geocodes in order to account for differences in access to healthcare across townships. These variables are the number of hospitals and clinics per 1,000 capita, the number of hospital beds per 1,000 capita, and the total number of medical personnel per 1,000 capita.

\subsection{Local environmental quality}

Our fourth dataset includes several variables that capture environmental quality in the insurant's county of residence. From the Taiwanese Environmental Protection Administration we obtained the level of atmospheric particulate matter, daily garbage weight per person, and the monthly amount falling dust per square kilometer. In addition, we collected the number of 
cars per square kilometer and the number of motorcycles per square kilometer from the Taiwanese Ministry of Transportation and Communications.

\subsection{Descriptive statistics}

Table 1 contains the average density of convenience stores and the average HHI for each year from 2002 to 2012, based on the 325 townships in Taiwan with at least one convenience store. The HHI decreases by 19.7\%, from 6,940 in 2002 to 5,567 in 2012 indicating greater competition between convenience store chains over time. Consistent with the decrease in the $\mathrm{HHI}$, there is a $56.5 \%$ increase in the density of convenience stores, from 0.24 convenience stores per 1,000 capita in 2002 to 0.37 convenience stores per 1,000 capita in 2012.

We provide a visualization of the regional disparities in inter-brand convenience store chain competition using a GIS map shown in Figure 1. Each township in Taiwan is assigned a color based on the average value of the HHI in our sample period. Townships without any convenience stores are marked with a checkered pattern, while the darkest colored areas have the highest HHI values (the least inter-brand competition) and the lightest colored areas have the lowest HHI values (the greatest inter-brand competition). Areas in the northwestern part of the island with the greatest amount of economic wealth and highest population density exhibit the greatest level of inter-brand competition, while mountainous and remote areas in the central and eastern parts of the island with the least economic wealth exhibit the lowest levels of competition.

The right-most columns of Table 1 contain annual measures of the healthcare use and expenditure variables. The rate of outpatient service use marginally increases from 2002 to 2005, but then decreases from a high of 0.93 to 0.89 in 2012. In contrast, outpatient expenditures increase steadily over the sample period. The use of inpatient services is relatively flat from 2002 to 2012, but expenditures increase dramatically. Whereas outpatient expenditures increase by 58\% over ten years, inpatient expenditures increase by $120 \%$. The utilization rate of prescription medications decreases from 2002 to 2012, but expenditures increase by $65 \%$. These increases in medical expenditures are high relative to other developed countries. For example, total per capita medical expenditures in the U.S. increased by $23 \%$ over the same period (CMS 2018).

Sample statistics for all explanatory variables are reported in Table 2. The average age of our sample is 40 years old, and the average monthly income is NT\$16,400 (approximately USD\$ 863, adjusted for purchasing power). Just under half of insurants work for a private firm or are self-employed, $4.6 \%$ are government employees, and $11.6 \%$ are farmers.

\section{Econometric model}

Following a large literature on medical expenditure modeling, we use a two-part model (TPM) to estimate the impact of convenience store outlet density and the HHI on medical 
expenditures (Jones 2000). The first part of the TPM accounts for a mass point in the expenditure distribution at zero expenditure that results from the failure by some to purchase medical care, and the second part of the model accounts for right-skewness in the distribution of expenditures among medical care users. It is common to specify the first part of model using a latent variable, $I_{i j t}^{*}$, to denote the propensity towards medical care use for insurant $i$ in township $j$ in year $t$. This is assumed to be a function of the characteristics of the convenience store market and other exogenous determinants:

$$
I_{i j t}^{*}=\alpha_{0}+\alpha_{1} \times A_{j t}+\alpha_{2} \times H H I_{j t}+X_{i j t}{ }^{\prime} \beta_{1}+Z_{j t}{ }^{\prime} \beta_{2}+u_{j}+T_{t}+u_{j} \times T R_{t}+\varepsilon_{i j t}
$$

The observed binary indicator $I_{i j t}=1$ if $I^{*}{ }_{i j t}>0$ and $I_{i j t}=0$ otherwise. The variable $A_{j t}$ denotes the density of convenience stores, and the variable $H H I_{j t}$ is the Herfindahl-Hirschman index capturing the degree of the inter-brand competition among the four major chains. $\boldsymbol{X}_{i j t}$ is a vector of socio-demographic characteristics of the insurants (age, gender, employment category and monthly income), $\boldsymbol{Z}_{j t}$ is a vector of township-level variables measuring the supply of medical services, township population and environmental quality, $u_{j}$ and $T_{t}$ are fixed effects for township and year, respectively, the interaction term $u_{j} \times T R_{t}$ is a townshipspecific linear time trend and $\varepsilon_{i j t}$ is the random error term. To test the sensitivity of the estimates to different functional specifications, we also estimate models with quadratic township-specific trends and models without any township-specific trend.

We specify equation (1) as a linear probability model (LPM) and denote the probability that an individual uses healthcare service as:

(2) $\operatorname{Pr}\left(I_{i j t}=1\right)=\alpha_{0}+\alpha_{1} \times A_{j t}+\alpha_{2} \times H H I_{j t}+X_{i j t}{ }^{\prime} \beta_{1}+Z_{j t}{ }^{\prime} \beta_{2}+u_{j}+T_{t}+u_{j} \times T R_{t}$

The second part of the TPM is the log of medical expenditures for the sample of individuals with medical care use, specified as:

(3) $\log \left(Y_{i j t} \mid I_{i j t}=1\right)=\gamma_{0}+\gamma_{1} \times A_{j t}+\gamma_{2} \times H H I_{j t}+X_{i j t}{ }^{\prime} \lambda_{1}+Z_{j t}{ }^{\prime} \lambda_{2}+u_{j}+T_{t}+u_{j} \times T R_{t}+v_{i j t}$

where $Y_{i j t}$ represents medical expenditures of the insurants, and $v_{i j t}$ is the random error term. Under the assumption that $v_{i j t}$ is homoscedastic, equations (2) and (3) can be combined to derive the unconditional mean of the medical expenditures as follows (Jones 2000):

$$
\begin{aligned}
& E\left(Y_{i j t}\right)=\operatorname{Pr}\left(I_{i j t}=1\right) \times E\left(Y_{i j t} \mid I_{i j t}=1\right)+\operatorname{Pr}\left(I_{i j t}=0\right) \times E\left(Y_{i j t} \mid I_{i j t}=0\right) \\
& =\operatorname{Pr}\left(I_{i j t}=1\right) \times \exp \left(Y_{i j t} \mid I_{i j t}=1\right) \times \theta
\end{aligned}
$$

where $\theta=\mathrm{E}\left(\exp \left(v_{i j t}\right)\right)$ is the smearing factor used to transform the estimates from the log 
scale back to the dollar scale. In our empirical application, we use Duan's nonparametric estimator for the smearing factor (Duan et al. 1983). In order to reduce the potential for heteroscedasticity to bias the estimates, we compute the smearing factor separately for each of the four NHI insurance programs (Manning 1998). The unconditional marginal effects for the two regressors of interest, convenience store density and HHI, are derived as follows:

$$
\frac{\partial E\left(Y_{i j t}\right)}{\partial A_{j t}}=\exp \left(Y_{i j t} \mid I_{i j t}=1\right) \times\left[\alpha_{1}+\gamma_{1} \times \operatorname{Pr}\left(I_{i j t}=1\right)\right] \times \theta
$$

$$
\frac{\partial E\left(Y_{i j t}\right)}{\partial H H I_{j t}}=\exp \left(Y_{i j t} \mid I_{i j t}=1\right) \times\left[\alpha_{2}+\gamma_{2} \times \operatorname{Pr}\left(I_{i j t}=1\right)\right] \times \theta
$$

The standard errors of these marginal efforts account for clustering at the township-level and are calculated using the delta method.

Although there are various nonlinear versions of the TPM that make use of a probit or logit in the first part of the model and a generalized linear model in the second part of the model, we use the linear version of the TPM because our specification includes township and year fixed effects and a township-specific linear time trend for identification. ${ }^{9}$ This ensures that the coefficients on store density and HHI are identified by variation within township over time that deviates from a linear trend. In the case of store density, this variation results from the entry or exit of convenience stores from the township. However, the identifying variation in HHI results from either changes in market share among outlets that maintain a presence in the township or from entry or exit. Given the significant growth in convenience store outlets over time across Taiwan, the entry of new outlets contributes more to the identifying variation of store density and HHI than exit from the market.

In order for our estimates to be unbiased the identifying variation in our models must be uncorrelated with the unobservable determinants of medical care utilization, such as community preferences for food and medical care. Since our models include township fixed effects, such a correlation will only exist if the unobservable determinants of medical care within townships are time-varying. And because we additionally include township-specific linear time trends in our models, these determinants must vary nonlinearly over time to generate a confounding correlation. Still, one concern is that the entry of a convenience store into a township could coincide with increases in unobserved community preferences for healthy food that could also affect medical care utilization through changes in health status or the demand for healthcare services. In order to determine whether our estimates of the effect of HHI are confounded by such a correlation, we estimate medical expenditure models on the

\footnotetext{
9 Nonlinear fixed effects models suffer from an "incidental parameters problem" where the number of parameters to be estimated increases with the sample size. This results in inconsistency of the estimated slope parameters (Greene 2004).
} 
sub-set of townships that did not experience a change in the number of convenience store outlets between 2008 and 2011. The identifying variation in HHI in these models is solely from changes in market share among existing stores (aggregated to the chain-level). We find that the estimated impact of $\mathrm{HHI}$ on medical expenditures using this subsample is qualitatively similar to the full sample, which suggests that unobserved community preferences for food and medical care are likely time-invariant or linearly increasing, and accounted for in our specification.

\section{Empirical results from healthcare utilization models}

\subsection{Main findings}

Appendix table A.1 contains coefficient estimates from the first part (use of services) and second part (log expenditures conditional on use) of our two-part models (TPM) for outpatient services, inpatient services and prescription medications. In accordance with our expectations, the socio-demographic characteristics of insurants are all significant determinants of medical care utilization. Coefficients on the variables capturing the supply of medical providers, however, are generally not precisely estimated, with the exception of medical personnel per 1,000 capita in the linear probability models of outpatient service and prescription drug use. This may be because the supply of providers in Taiwan is relatively high, and insurance through the NHI program is comprehensive, mitigating access problems in most areas. For example, the number of hospital beds per 1,000 capita during the sample period was 7.5 in Taiwan (Table 2), but was 5.9 in other high income countries in 2005 (World Bank 2017). In contrast, several variables measuring pollution and population density are statistically significant in both the service use and expenditure equations. For example, an increase of 1,000 motorcycles per square kilometer (72 percent of the mean) increases the probability of outpatient services by 5.6 percentage points, and outpatient expenditures by 6.7 percent.

Table 3 contains marginal effect estimates from TPM for healthcare use and expenditures for the full sample, urban sample and rural sample. The marginal effects for the $\mathrm{HHI}$ and store density variable for the first part of the model are measured in percentage points, while for medical expenditures we report the unconditional marginal effects calculated across both parts of the model, measured in 2012 NT\$. ${ }^{10}$ A one unit change in store density represents an increase of one store per 1000 capita, which is just over three times the sample mean. The HHI variable included in our empirical models is re-scaled between 0 and 1 , so a one unit change corresponds to a change in market competition from perfect competition to monopoly. Finally, we also divide each marginal effect by the sample

\footnotetext{
10 Note that the coefficient estimates in the first part of the TPM are equivalent to marginal effects because the model is linear.
} 
average value of the dependent variable in order to convert the magnitudes of the marginal effects to percentages.

The marginal effects for HHI are positive and statistically significant in the equations for outpatient services and prescription drugs, but imprecisely estimated in the model for inpatient services. A change in inter-brand competition between convenience store chains from perfect competition to monopoly results in a 2 percentage point (2.2\%) increase in the use of outpatient services and an increase in outpatient medical expenditures of NT\$ 200 per year (3.1\%). The same change in market competition results in a proportionally greater increase in prescription drug use and expenditures. In particular, moving from a perfectly competition convenience store market to monopoly increases drug use by 3.2 percentage points (3.8\%) and expenditures by NT\$ 34 per year (3.6\%). Because a change in market structure from perfect competition to monopoly is unlikely to be observed in most empirical samples, it may be more meaningful to consider the effect of a 1,000 unit change in the HHI, which is 73 percent of the historical change in the HHI in Taiwan between 2002 and 2012. In this case, a 1,000 unit increase would result in a $0.31 \%$ outpatient medical expenditures, and a $0.36 \%$ increase in prescription drug expenditures.

The marginal effects for convenience store density are consistent with the effects for market competition in that an increase in the density of outlets decreases the use and cost of outpatient services and prescription drug expenditures. The magnitudes of the effects, however, are much smaller. An increase of one store per 1,000 capita is associated with a small increase in the use of outpatient care of just $0.14 \%$ and has no detectable effect on the rate of prescription drug use. Likewise, a one unit increase in store density results in a decrease of NT\$ 66 per year (1\%) in outpatient service expenditures and a decrease of NT\$ 2.7 per year $(0.27 \%)$ in prescription drug expenditures. If we consider a 0.1 unit increase in store density, which is 75\% of the observed change in store density between 2002 and 2012, expenditures for outpatient services decrease by $0.1 \%$ and expenditures for prescription drugs decrease by $0.03 \%$.

\subsection{Estimates by population density}

Because the average levels of inter-brand competition and convenience store density are both higher in urban areas, changes in competition and store density may have different effects on medical care utilization in urban and rural areas. ${ }^{11}$ We investigate this possibility by estimating separate models on the 135 townships in urban areas and the 190 rural townships. ${ }^{12}$ The results in Table 3 indicate that changes in inter-brand competition have a larger effect in rural areas than urban areas, particularly in the case of outpatient services. In

\footnotetext{
11 In our sample, the average value of HHI is 0.47 in urban areas and 0.64 in rural areas. The average value of convenience store density is 0.92 in urban areas and 0.14 in rural areas.

12 Our definition of rural and urban areas follows the categorization of Chang and Fu (2006) whose classification approach has been used in many government reports in Taiwan.
} 
particular, a 1,000 unit change in the HHI results in a $0.32 \%$ increase in outpatient service use and a $0.39 \%$ increase in outpatient expenditures in rural areas, but a $0.23 \%$ increase in use and $0.30 \%$ increase in expenditures in urban areas. This urban-rural difference is less pronounced for prescription drug use and expenditures. In addition, changes in convenience store density have a larger effect on prescription drug use in urban than rural areas, although the opposite is true for prescription drug expenditures. Furthermore, increases in store density lead to larger reductions in outpatient service use and expenditures in rural areas than urban areas.

\subsection{Estimates by age group}

Next, we investigate whether there are differences in the effects of convenience store competition and access across age groups. Since convenience stores mainly sell ready-to-eat food, one might expect changes in market structure to have a larger effect on working age adults who purchase their lunches at food outlets. Likewise, access to convenience stores may be relatively more important for the elderly, given their sometimes limited mobility and greater reliance on public transportation. The separate estimates by age group reported in Table 4 suggest that changes in competition do generally affect the medical care use and costs of working age adults more than children or the elderly. For example, a 1,000 unit change in the $\mathrm{HHI}$ is associated with a $0.32 \%$ increase in prescription drug expenditures among working age adults, but a $0.22 \%$ increase among children and a $0.23 \%$ increase among the elderly. The only exception is the effect of competition on the use of prescription drugs, which is larger among children. The impact of convenience store density is somewhat less precisely estimated on these smaller subsamples, and we find only limited evidence that store density matters more for the elderly. While the impact of an increase in 0.1 stores per 1,000 capita reduces outpatient service use the most among the elderly (0.05\%), the same change reduces prescription drug use the most among working age adults $(0.11 \%)$.

\subsection{Robustness checks}

In order to gain insight into the potential for endogeneity to bias in our medical expenditure estimates, we subjected our main set of results to several robustness checks. First, in Table 5, we compare our preferred specification containing township fixed effects and township-specific linear trends to other possible specifications. Model A of Table 5 is a simple OLS model of medical care use and expenditures with our full set of control variables and year fixed effects, but without township fixed effects. In model B we add township fixed effects to these models, and in models $\mathrm{C}$ and $\mathrm{D}$ we replace the year fixed effects with township-specific linear time trends and township-specific quadratic time trends, respectively. The largest difference in the coefficients for the outpatient services model is between the OLS models without township fixed effects in model A and the models with 
township fixed effects in the other columns. There is evidence that the coefficients on both HHI and store density are negatively biased in the models without township fixed effects. When the dependent variables are prescription drug use and expenditures the OLS estimates without township fixed effects are less precisely estimated. Nonetheless, there still appears to be a negative bias in the OLS models without township fixed effects. Among the models for both types of medical care that do include township fixed effects, the estimates are not sensitive to whether the township-specific time trend is specified as linear or quadratic (models C and D).

While the inclusion of township fixed effects can account for unobservable factors that are township-specific and time invariant, there is still the concern that (nonlinear) timevarying unobserved factors could result in biased estimates. This could occur if, for example, convenience store chains were more likely to open new stores in markets where there were growing preferences for their products, and simultaneously for other inputs to health production, resulting in a decline in medical care utilization. In order to investigate this possibility we estimate our preferred specification with township fixed effects and townshipspecific linear time trends on the subset of 61 townships during 2008-2011 without entry or exit of convenience store outlets. The store density variable is dropped from this specification due to perfect collinearity with the township fixed effect, and variation in $\mathrm{HHI}$ is due solely to changes in market share among the pre-existing stores. Table 6 contains the marginal effects of the HHI variable estimated from these models, which are very similar to the estimates from the full sample reported in Table 3.

As a final robustness check, we investigate whether changes in convenience store access and competition disproportionately affect expenditures for certain types of medical care. While nearly all major categories of medical services could be affected by dietary change, some diseases are more directly affected than others. We use information contained in the NHI health claim profiles to estimate models for outpatient services and prescription drugs from four major NHI departments: Digestive gastroeneterology, orthopedics, cardiology and general surgery (Table 7). The only department where decreases in inter-band competition increase the use and cost of medical services is the department of digestive gastroeneterology. The magnitude of the marginal effects for HHI on use and expenditures under this department are slightly larger than the marginal effects for all types of medical care combined. Of the four departments, expenditures associate with digestive gastroeneterology treatment are arguably the most directly linked to diet, followed by cardiology. For example, proton pump inhibitors, which are used to treat gastroesophageal reflux disease, account for a large share of prescription drug expenditures in the U.S. (Stagnitti 2007).

These robustness checks support our main finding that greater inter-brand competition between convenience stores chains and higher store density are associated with reductions in medical care expenditures for outpatient services and prescription drugs. Next, we consider 
the mechanisms through which changes in both competition between convenience stores and their accessibility affect medical spending.

\section{Potential mechanisms and mediators}

There are several strands of the literature that suggest potential mechanisms responsible for our reduced form medical expenditure results. First, a sizable body of literature demonstrates that food outlet density affects food consumption decisions and body weight (e.g., Anderson and Matsa 2011; Bonanno and Goetz 2012; Currie et al. 2010; Dunn 2010; Fitzpatrick et al. 2015; Gordan-Larson 2014; Rose and Richards 2004; Courtemanche and Carden 2011; Powell et al. 2007). In general, these studies suggest better access to supermarkets increases the consumption of healthier foods, such as fruits and vegetables, while access to fast food restaurants increases rates of obesity.

Studies also find that changes in food prices, some of which are brought on through price competition, impact food consumption and body weight. For example, Courtemanche and Carden (2011) find that the proliferation of Wal-Mart supercenters has led to an increase in body weight of local residents, due in part to price competition with other food retailers and lower prices for goods that complement sedentary lifestyles. Powell and Chaloupka (2009) review fifteen articles published in the Medline, PubMed, Econlit and PAIS databases between 1990 and 2008, and conclude that there are statistically significant associations between food and restaurant prices or taxes and body weight, although the effects are generally small.

These studies collectively suggest that changes in food consumption and body weight may mediate the relationships we observe between food outlet density, inter-brand convenience store competition and medical care utilization. Additional evidence in support of the mediating effect of obesity is provided by studies finding that obesity significantly increases the cost of medical care in the United States (e.g., Cawley and Meyerhoefer 2012; Cawley et al. 2015), Australia (Buchmueller and Johar 2015), and Taiwan (Hu et al. 2008; Chu et al. 2010). In particular, Cawley and Meyerhoefer (2012) find that obesity raises perperson medical care costs by US\$ 2,741 per year, and Cawley et al. (2015) predict that the aggregate cost of obesity in the U.S. exceeds US\$ 315 billion. Although studies linking food consumption directly to medical care costs are less common, Frazao (1999) concludes that healthier diets might reduce medical care costs in the U.S. by US\$ 71 billion per year.

\subsection{Data and variable construction}

The dataset we use to explore the mediating effects of food consumption and obesity is the 2005 National Health Interview Survey in Taiwan (NHIST). ${ }^{13}$ The NHIST is a nationally

\footnotetext{
${ }^{13}$ Ideally, we would like our dataset to contain food price information, but there are no township-specific food price data in Taiwan.
} 
representative survey of the non-institutionalized population conducted by the National Health Research Institute of Taiwan. Using a multistage stratified sampling scheme, approximately 5,000 households were selected for face-to-face interviews. ${ }^{14}$ After deleting observations with missing values, our final sample consists of 22,423 respondents.

From the NHIST we derive several measures of food consumption and body weight. The survey contains self-reported height and weight, which we use to construct body mass index (BMI), defined as the ratio of weight (in kilogram) to height squared (in meters). In accordance with standards established by the Taiwan Department of Health, adults are considered obese if they have a BMI in excess of 27, while childhood obesity is determined using cutoff points on the age and gender-specific BMI distribution. ${ }^{15}$ We create a binary indicator for obesity as well as the continuous BMI z-score for both adults and children.

Food consumption information in the NHIST is collected through the following question: "How often do you or your child consume the following food item?" Possible responses include "never”, "seldom”, “sometimes”, “often”, and "always”. The question is asked for 21 food items, which we aggregate into eight major groups: fruits and vegetables; less sugary drinks (including yogurt, milk and soymilk); sugar-sweetened drinks; proteins (including meat, poultry, fish and other seafood, egg, and soy products), fast food (including hamburger, pizza and fries); rice and noodles; sweets (including cookies, chocolate, cake, bread, and ice cream); and coffee and tea. We then calculate an index measuring the frequency of food consumption for each of the five food groups by assigning values 0-4 to the qualitative response categories (i.e. 0 for "never" and 4 for "always"). Therefore, higher index values represent more frequent consumption.

We merge the 2005 values of the HHI, convenience store density, variables measuring the supply of medical providers, and township population and land area to the NHIST using township geocodes. Using information contained in the NHIST, we construct several variables to control for the socio-demographic characteristics of respondents. These include binary indicators for male, employment, education (i.e. primary, junior high school, senior high school, college and graduate) and the 23 administrative counties in Taiwan. We also construct continuous variables for age, monthly family income and the number of people living in the household. Sample statistics for both the dependent and explanatory variables (excluding county fixed effects) are reported in Table 8.

\subsection{Models of obesity and BMI z-score}

Table 9 contains the estimation results from a linear probability model for obesity and OLS model of BMI z-score estimated using the full NHIST sample (including both adults and

\footnotetext{
14 A detailed description of the NHIST survey design can be found at http://nhis.nhri.org.tw/

15 The cutoff points for determining childhood obesity in Taiwan can be found at http://www.vghtpe.gov.tw/ nutr/forum/forum02/bmi2.htm.
} 
children) as well as the urban and rural subsamples (The full set of coefficient estimates for these models is reported in Appendix Table A.2). Sampling weights are included in model estimation to ensure that the estimates are nationally representative, and the standard errors of the parameters are clustered at the county level. We report the coefficients for each regressor and the marginal effects for $\mathrm{HHI}$ and store density expressed as a percentage of the sample mean of the dependent variable. An increase in inter-brand competition of convenience store chains from perfect competition to monopoly is associated with a 3.4 percentage point increase in the probability of obesity, which is $23 \%$ of the mean obesity prevalence. This effect is more than twice as large in the rural subsample (34\%) than the urban subsample (15\%). A more typical change of 1,000 HHI units is associated with an overall $2.3 \%$ increase in obesity and a 3.4\% and 1.5\% increase in the rural and urban sub-samples, respectively. The effect of store density is negatively associated with obesity, and is more precisely estimates in the rural subsample than the urban subsample. In particular, the addition of one convenience store per 1,000 capita, which is 2.4 times the overall average number of stores, is associated with a $10 \%$ reduction in the probability of obesity in the full sample, and a $17 \%$ reduction in the rural subsample. Therefore, a more typical change in store density of 0.1 units is associated with $1 \%$ reduction in obesity in the full sample and a $1.7 \%$ reduction in the rural subsample. Findings from the models for BMI z-score are analogous to the models for obesity: reductions in competition and decreases in store density are associated with larger increases in BMI in rural areas. However, this conclusion is based on a comparison of the rural estimates to the full sample estimates because the estimates from the urban subsample are imprecise.

We next estimate models of obesity and BMI z-score separately for children, working age adults, and the elderly. Given that the effects of inter-brand competition and store density on medical expenditures are concentrated among working age adults, we expect the correlated between obesity and these variables also to be strongest among working age adults. The estimates reported in Table 9 confirm this hypothesis. While convenience story density is not precisely estimated in any of the models, there is a large and statistically significant correlation between $\mathrm{HHI}$ and both obesity and BMI z-score for adults, but no precisely estimated effect for children or the elderly.

\subsection{Models of food consumption}

Estimation results for the frequency of food consumption equations for the full sample as well as the rural and urban subsamples are presented in Table 10. Again, we use sampling weights and cluster the standard errors at the county level. In all samples, higher values of the $\mathrm{HHI}$ indicating less inter-brand competition are negatively associated with the consumption of relatively healthy foods, including fruits and vegetables, less sugary drinks, and coffee and tea, as well as one less healthy group of foods, sweets. Less competition is also positively 
associated with the consumption of proteins and rice and noodles, as well as the consumption of two less healthy food categories: sugary drinks and fast food. The patter of associations is the same for convenience store density, although the sign of the marginal effects is reversed because greater density is generally correlated with more competition.

The magnitude of a one unit change in HHI is greatest for coffee and tea and smallest for rice and noodles. One reason for this is that coffee sales alone account for $6 \%$ of all convenience store sales, and 29\% of private label product sales (Appendix Table A.3). Because convenience store chains can only charge different prices for private label products, we expect the strongest associations with changes in competition for products such as coffee, non-alcoholic drinks and meal boxes. While meal boxes do not fit neatly within any of the food categories specified in the NHIST, we do have data on non-alcoholic drinks, which account for $25 \%$ of convenience store sales and $12 \%$ of private label product sales (Appendix Table A.3). The increase in the consumption in less sugary drinks brought about by greater competition is likely due to competitive forces lowering the prices of these drinks. However, the substitution away from sugary drinks that results when competition increases may be tied to the substitution away from fast food; a major competitor of ready-to-eat food at convenience stores.

There are some differences in the magnitudes of the marginal effects between the urban and rural samples. Greater convenience store competition is associated with a larger decrease in the consumption of sugary drinks and a larger increase in the consumption of less sugary drinks in urban areas than rural areas. This may be because competition with fast food restaurants is more intense in urban than rural areas. In contrast, competition is associated with a larger increase in the consumption of sweets in rural areas than in urban areas.

Table 11 contains marginal effects from the food frequency equations estimated separately for the three different age groups. Despite the fact that the medical expenditure and obesity effects of changes in competition are concentrated among the working age population, we find some large and significant correlations between HHI and store density and food consumption for all age groups. We do note, however, that the overall precision of the estimates is greatest for working age adults. The largest correlation between a food group and both HHI and store density is for fast food. For example, a 1,000 unit increase in the HHI is associated with a $1.6 \%$ decrease in fast food consumption among working age adults, while 0.1 additional convenience stores per 1,000 capita is associated with a $1.3 \%$ decrease. Again, fast food establishments compete heavily with convenience stores in the ready-to-eat food market, so it stands to reason that lower prices at convenience stores for items such as meal boxes (or their greater accessibility) would lead to substitution away from fast food in favor of food provided by convenience stores. 


\section{Discussion and conclusions}

We find that higher levels of inter-brand competition among convenience store chains reduce the use and cost of outpatient medical services and prescription drugs. Utilization of prescription drugs is most responsive to changes in the competitive landscape, although the magnitudes of the marginal effects are only slightly smaller for outpatient services. In particular, a 1,000 unit change in the HHI reduces annual prescription drug expenditures by $0.36 \%$ and annual expenditures on outpatient services by $0.31 \%$. These results are robust to the specification of township-specific time trends as linear or quadratic, and to differences in the variation in HHI used to identify the models. There are several potential reasons why higher levels of convenience store competition could reduce medical care expenditures. Most of the competition among convenience stores in Taiwan is through the sale of private label products that are offered exclusively by convenience store chains. These items are predominantly ready-to-eat foods and nonalcoholic drinks. In fact, private label products represent $75 \%$ of the meal boxes, sandwiches and other ready-to-eat foods sold at convenience stores (TFTC 2016). In order to differentiate their products from food away from home sold at Chinese restaurants, lunch shops and traditional food vendors, convenience stores provide nutritional information for private label products in the form of detailed nutrition labels, and advertise the healthfulness and quality of their products.

Increased competition presumably decreases the price of these products relative to other food away from home, and increases the quality of service provision. Both should cause substitution away from the less healthy foods sold by other food away from home providers in favor of the healthier food sold at convenience stores.

Overall trends in the growth of convenience stores relative to other retail food outlets support a shift in consumption patterns in favor of the former. The increase in the number of convenience stores between 1999 and 2016 was more than two and half times greater than the increase in the number of restaurants, and over six times greater than the increase in other food outlets (TFTC 2016). Furthermore, convenience store sales grew nearly 20\% between 2013 and 2016, while the sales of meal shops and traditional food vendors contracted (TMF 2017). Our analysis of household survey data support the hypothesis that consumers substituted relatively more healthy private label products at convenience stores for other types of food away from home. In particular, we find that individuals living in areas with perfectly competitive markets are $23 \%$ less likely to be obese than individuals who live in monopoly markets. More competition is associated with a reduction in the consumption of fast food and sugary drinks, and is associated with increases in the consumption of fruits and vegetables, less sugary drinks and coffee. We also find that the consumption of sweets rises with convenience competition, but the overall shift in consumption patterns appears to be towards healthy foods. A final piece of evidence that supports the mediating role of food consumption in the relationship between competition and medical care costs is the finding 
that convenience store competition disproportionately reduces medical services provided by the department of digestive gastroenterology.

By analyzing subgroups of the population, we demonstrate that decreases in medical care expenditures brought about by convenience store competition are concentrated among working age adults; so too are the mediating decreases in obesity and increases in the consumption of healthy foods. One possibility is that convenience stores target the lunch purchases of working adults through attractive pricing of meal boxes and nonalcoholic drinks that are relatively low in calories, with competition intensifying this practice. We also uncover modest differences in the effects of competition between urban and rural areas. More competition reduces the use and cost of outpatient medical services and prescription drugs more in rural areas. This may not necessarily reflect intrinsic differences in the characteristics of urban and rural locales, but rather heterogeneity in the effect of competition at different points in the HHI distribution. The average HHI in urban areas during our sample period is 5,102, while the average HHI in rural areas is 6,810. Therefore, increases in convenience store competition in rural areas typically occur in markets with more initial concentration. At the same time, convenience stores represent a larger proportion of establishments offering ready-to-eat food or food away from home in rural areas (63\% of establishments) than urban areas (49\% of establishments) (TFTC 2016). Consistent with the medical expenditure results, the correlation between $\mathrm{HHI}$ and obesity is also larger in rural areas, although the food frequency analysis shows stronger correlations between food intake and HHI in urban areas.

We independently assess the impact of changes in food accessibility through higher levels of convenience store density on medical care utilization. Our findings are also consistent with the hypothesis that convenience stores provide relatively healthier food options than other sellers of food away from home. Specifically, increases in store density reduce the cost of outpatient services and prescription drugs, and do so the most for outpatient services in rural areas. This is likely because the average density of convenience stores is much lower in rural areas than urban areas. As with HHI, evidence from household survey data support the hypothesis that increases in food story density reduce the probability of obesity through a shift towards the consumption of relatively healthy foods. While we expect that greater store density might impact medical care use the most for the elderly, whose ability to travel to buy food is often diminished, we find only limited support for this hypothesis. This may be because the mechanisms used by the elderly to purchase food (e.g. through younger relatives) are not highly sensitive to store location.

Our study has some limitations. The growth of the convenience store industry in Taiwan over the sample period was strong and steady. There are no obvious natural experiments to exploit for identification, such as significant regulatory action, or the rapid entry of a formidable new competitor into the market. ${ }^{16}$ As a result, we rely on changes in competition

${ }^{16}$ For example, several studies in the U.S. use the entry of Walmart in the supermarket industry as a natural 
over time within market areas that deviate from linear trends for identification. Our fixed effects specifications remove the bias from unobservable time-invariant market characteristics that are correlated with both medical care utilization and competition, but they cannot control for time-varying confounding factors that were not linearly increasing within townships. If, for example, the entry of convenience stores into certain markets was in response to rapidly changing preferences for healthier lifestyles, then our estimates could be biased. Although the bias in this specific example is difficult to determine, we would expect it to attenuate our effects under the assumption that greater preferences for health would jointly increase the demand for healthcare and the demand for convenience store products. Nonetheless, models that don't rely on the entry of stores to generate identifying variation in HHI yield similar results to those that do, which suggests that convenience store chains may not have specifically targeted communities with greater preferences for health. Another limitation of our reduced form approach is that we cannot calculate the changes in consumer welfare that resulted from the increase in convenience store competition in Taiwan. Doing so would require estimates of structural parameters on firm costs and consumer demand.

Despite these limitations, our study makes an important contribution to a sparse literature on the effects of food outlet competition on health and medical care utilization. While the previous literature has focused on access to healthy foods through greater food outlet density, our results suggest that increased competition between providers of food away from home reduces medical care costs more than improved access to healthy food through an increase in the number of convenience stores. The best way to see this is to consider how the change in HHI and convenience store density in Taiwan from 2002 to 2012 impacted medical care costs. Over this time period competition between convenience store chains increased 1,373 HHI units and the number of convenience stores per 1,000 people increased by 0.13 . Based on our estimates, the increase in competition lowered medical expenditures on outpatient services by $0.44 \%$ and expenditures on prescription drugs by $0.50 \%$. However, the increase in the number of convenience stores over the same period lowered outpatient medical expenditures by only $0.02 \%$ and prescription drug expenditures by only $0.04 \%$. Even in 2002 the number of stores in Taiwan ( 0.24 per 1,000 people) was relatively high, which might explain why adding more stores had little impact. It is also possible that many new stores were located next to existing stores in order to take advantage of agglomeration economies. This would not be surprising given the popularity of agglomeration among chain stores due to externalities that improve efficiency and productivity (e.g., Devereux, Griffith and Simpson 2007; Sevtsuk 2014). These considerations notwithstanding, our results highlight the importance of competition in increasing access to healthy foods. Although we are unable to determine whether lower prices or improvements in service quality were responsible for the resulting consumption shift, we suspect that lower food costs were most 
important. This is particularly true if one considers the total cost of acquiring food at convenience stores, including product prices and time costs. ${ }^{17}$

Despite the fact that we find credible and consistent reductions in medical expenditures from greater convenience store competition, the implications for competition policy are not substantial. The increase in competition over the ten years of our sample period reduced aggregate medical expenditures in Taiwan by NT\$ 55 billion. While this is a non-trivial amount, if one considers the extent that the competitive landscape could be altered by typical competition policies, the scope for medical expenditure savings from pro-competitive initiatives is modest. Nonetheless, it does suggests that medical care costs could be an important secondary consideration when determining competition policies. Likewise, policies designed to promote the consumption of healthy foods are more likely to result in lower rates of obesity and reductions in medical care costs if they do not limit competition between store chains specializing in the sale of such foods.

A final implication of our results is related to antitrust regulation applied to the food away from home industry. In particular, the substitution of foods between convenience stores and other food away from home providers suggests a broader set of competitors should be used to define the market for convenience store food than is typically the case. In this sense our results point to the need to re-evaluate the traditional boundaries of competition policy, such as in the case of a merger between two supermarkets in Taiwan where a broader set of retailers was used to define market shares. ${ }^{18}$ The need to revise antitrust regulations in this manner is not unique to Taiwan. For example, Ellickson, Grieco and Khvastunov (2017) found that food outlets offering healthy products, such as supermarkets and premium organic firms, often compete with a larger set of retailers than those recognized by regulators in U.S. antitrust cases. Of course, mergers in the convenience store industry that ultimately limit competition would result in marginally higher medical care costs for the citizens of Taiwan, which is also something that regulators must weigh in their decisions.

\footnotetext{
17 For example, the amount of time required to purchase ready-to-eat food at a convenience store and consume it on-site is less than the amount of time required to eat at a Chinese restaurant.

18 This merger is described in http://www.appledaily.com.tw/realtimenews/article/new/20160127/784457/
} 


\section{References}

Allcott, H., Diamond, R., Dube, J-P. 2017. The geography of poverty and nutrition: food deserts and food choices across the United States. NBER Working Paper No. 24094.

Anderson, M., Matsa, D. 2011. Are restaurants really supersizing America? American Economic Association: American Economic Journal: Applied Economics 3(1): 152188.

Biener, A., Cawley, J., Meyerhoefer, C. 2017. The impact of obesity on medical care costs and labor market outcomes in the US. Clinical Chemistry doi: 10.1373/clinchem.2017.272450, published November 2017.

Blanchard, T. and Lyson, T. 2002 Access to low cost groceries in nonmetropolitan counties: large retailers and the creation of food deserts. Accessed at http://srdc.msstate.edu/trainings/presentations_archive/2002/2002_blanchard.pdf.

Blanchard, T. and Matthews, T. 2007. Retail concentration, food deserts and food disadvantaged communities in rural America. In C. Hinrichs, and T. Lyson, eds. Remaking the North American Food System, pp. 201-215. Lincoln: University of Nebraska Press.

Bloom, D., Cafiero, E., Jané-Llopis, E., Abrahams-Gessel, S., Bloom, L., Fathima, S., Feigl, A., Gaziano, T., Mowafi, M., Pandya, A., Prettner, K., Rosenberg, L., Seligman, B., Stein, A., Weinstein, C. 2011. The global economic burden of non-communicable diseases. Geneva: World Economic Forum.

Bonanno, A., Goetz, S. 2012. Food store density, nutrition education, eating habits and obesity. International Food and Agribusiness Management Review 15(4): 1-26.

Buchmueller, T., Jihar, M. 2015. Obesity and health expenditures: Evidence from Australia. Economics and Human Biology 17: 42-58.

Cawley J., Meyerhoefer, C. 2012. The medical care costs of obesity: An instrumental variables approach. Journal of Health Economics 31(1): 219-230.

Cawley J., Meyerhoefer, C., Biener, A., Hammer, M., Wintfeld, N. 2015. Savings in medical expenditures associated with reductions in body mass index among adults with obesity, by diabetes status. Pharmacoeconomics 33: 707-722.

Centers for Medicare and Medicaid Services (CMS). 2018. National health expenditure data. Accessed January 3, 2018 at https:/www.cms.gov/Research-Statistics-Data-andSystems/Statistics-Trends-andReports/NationalHealthExpendData/NationalHealthAccountsHistorical.html

Chang, F., Dawson, J. 2007. The acceptance and adaptation of a foreign retail format: The case of the convenience store in Taiwan in the 1980s and 1990s. International Journal of Entrepreneurship and Small Business 4(1): 17 -40.

Chang, Y., Fu, Y. 2006. Taiwan Social Chang Survey. Institute of Sociology, Academia Sinica, Taiwan. 
Cheng, J., Blankson, C., Sutikno, B., Wang, M. 2009. Hybrid convenience stores - the changing role of convenience stores in Taiwan. Asia Pacific Journal of Marketing and Logistics 21(3): 417 - 432

Chiang, T. 1997. Taiwan’s 1996 healthcare reform. Health Policy 39: 225-239.

Chiu, P. 2006. Taiwan's dense market pits convenience stores in tight battle. Wall Street Journal, p. 5.

Chou, S., Grossman, M., Saffer, H. 2004. An economic analysis of adult obesity: results from the Behavioral Risk Factor Surveillance System. Journal of Health Economics 23(3): 565-587

Chu, N., Wang, S., Chang, H., Wu, D. 2010. Medical services utilization and expenditure of obesity-related disorders in Taiwanese adults. Value in Health 13(6): 829-836.

Courtemanche, C., Carden, A. 2011. Supersizing supercenters? The impact of Walmart Supercenters on body mass index and obesity. Journal of Urban Economics 69(2): 165181.

Currie, J., Vigna, D., Moretti, E., Pathania, V. 2010. The effect of fast food restaurants on obesity and weight gain. American Economic Journal: Economic Policy 2(3): 32-63.

Davis, B., Carpenter, C. 2009. Proximity of fast-food restaurants to schools and adolescent obesity. American Journal of Public Health 99(3): 505-510.

Devereux, M., Griffith, R., Simpson, H. 2007. Firm location decisions, regional grants and agglomeration externalities. Journal of Public Economics 91: 413-435.

Dunn, R. 2010. The effect of fast food availability on obesity: An analysis by gender, racial and residential location. American Journal of Agricultural Economics 92(4): 11491164.

Ellickson, P., Greico, P., Khvastunov, O. 2017. Measuring competition in spatial retail. Accessed at http://personal.psu.edu/plg15/egk_grocery_Feb2017.pdf.

Frazao, E. 1999. High costs of poor eating patterns in the United States. AIB-750. U.S. Department of Agriculture, Economic Research Service, Washington DC, USA.

Fitzpatrick, K., Greenhalgh-Stanley, N., Ver Ploeg, M. 2015. The impact of food deserts on food insufficiency and SNAP participation among the elderly. American Journal of Agricultural Economics 98(1): 19-40

Galvez, G., Hong, L., Choi, E., Liao, L., Godbold, G., Brenner, B. 2009. Childhood obesity and neighborhood food-store availability in an inner-city community. Academic Pediatrics 9(5): 339-343.

Gaynor, M., Town, R. 2011. Competition in health care markets. In Pauly, M., McGuire, T., and P. Barro (eds), Handbook of Health Economics. Vol 2. pp. 499-637. Amsterdam: Elsevier.

Green, W. 2004. The behaviour of the maximum likelihood estimator of limited dependent variable models in the presence of fixed effects. Econometrics Journal 7: 98-119. 
Gordan-Larson, P. 2014. Food availability/convenience and obesity. Advanced Nutrition 5(6): 809-817.

Handbury, J., Rahkovsky, I., Schnell, M. 2016. Is the focus on food deserts fruitless? Retail access and food purchases across the socioeconomic spectrum. NBER Working Paper No. 21126.

Hausman, J. Leibtag, E., 2007. Consumer benefits from increased competition in shopping outlets: measuring the effect of Wal-mart. Journal of Applied Econometrics 22: 11571177.

Hsu, Y., Huang, H. 2006. Alternative futures for convenience store management in Asia: an e-business perspective. Journal of Futures Studies 10(3): 79-88.

Hu, H., Chou, Y., Chou, P., Lee, C., Lee, M., Huang, N. 2008. Association between obesity and medical care expenditure among Taiwanese adults. Asia Pacific Journal of Clinic Nutrition 17(3): 492-504.

Huarng, K., Yu, T. 2014. Analysis of franchisors' expansion strategies and competition. The Service Industries Journal 34(9-10): 856-866.

Hung, H. 2005. The King of Marketing Channels - The Way 7-Eleven Manage its Business. Weide Publishing Co., Taipei, Taiwan.

Laraia, B., Siega-Riz, A., Kaufman, J. Jones, S. 2004. Proximity of supermarkets is positively associated with diet quality index for pregnancy. Preventive Medicine 39: 869-875.

Lien, H. 2011. How to Construct Social-Economic Variables from National Health Insurance Data. Journal of Social Sciences and Philosophy 23(3): 371-398.

Marlow, M. 2015. Big box stores and obesity. Applied Economics Letters 22(12): 938-944.

Manning, W. 1998, The logged dependent variable, heteroscedasticity, and the retransformation problem. Journal of Health Economics17:283-95.

Matsa, D. 2011. Competition and Product Quality in the Supermarket Industry. Quarterly Journal of Economics 126(3): 1539-1591.

Meyerhoefer, C., Leibtag, E. 2010. A spoonful of sugar helps the medicine go down: The relationship between food prices and medical expenditures on diabetes. American Journal of Agricultural Economics 92(5): 1271-1282

Morland, K., Roux, A., Wing, S. 2006. Supermarkets, other food stores, and obesity: the atherosclerosis risk in communities study. American Journal of Preventive Medicine 30(4): 333-338.

Morland, K. Wing, S., Roux, A. 2002. The contextual effect of the local food environment on residents' diets: the atherosclerosis risk in communities study. American Journal of Public Health 92(11): 1761-1767.

Jones, A. 2000. Health econometrics. In Culyer, A. and J. Newhouse (eds), Handbook of Health Economics. Vol 1. pp. 265-344. Amsterdam: Elsevier. 
Powell, L. 2009. Fast food costs and adolescent body mass index: evidence from panel data. Journal of Health Economics 28(5): 963-970.

Powell, L., Chaloupka, F. 2009. Food prices and obesity: evidence and policy implications for taxes and subsidies. Milbank Quarterly 87(1): 229-257.

Powell, L., Auld, C., Chaloupka, F., O'Malley, P., Johnston, L. 2007. Associations between access to food stores and adolescent body mass index. American Journal of Prevention Medicine 33(4S): S301-S307.

Rose, D., Richards, R. 2004. Food store access and household fruit and vegetable use among participants in the US food stamp program. Public Health and Nutrition 7(8): 10811088.

Schafft, K., Jensen, E., Hinrichs, C. 2009. Food deserts and overweight schoolchildren: Evidence from Pennsylvania. Rural Sociology 74(2): 154-177.

Schroeter, C., Lusk, J., Tyner, W. 2008. Determining the impact of food price and income changes on body weight. Journal of Health Economics 27(1): 45-68

Sevtsuk, A. 2014. Location and agglomeration: The distribution of retail and food business in dense urban environment. Journal of Planning Education and Research 34(3): 374-393.

Stagnitti, M. 2007. The top five prescription drugs ranked by total expense for children, adults, and the elderly, 2004. MEPS Statistical Brief \#180. U.S. Agency for Healthcare Research and Quality, Washington DC, USA.

Taiwan Chain Stores and Franchise Association (2015). Taiwan Chain Store Almanac. Taiwan Fair Trade Commission (TFTC). 2016. Annual Report of the Convenience Store Market in Taiwan. Published by the Taiwan Fair Trade Commission, Taipei, Taiwan. Taiwan Ministry of Finance (TMF). 2017. Trade and Food Service Operations Surveys. Published by Taiwan Ministry of Finance, Taipei, Taiwan.

Taiwan Today. 2014. Taiwan top for convenience store density, China Times, 2014.2.17. Thomsen, M., Nayaga, R., Alviuola, P., Rouse, H. 2016. The effect of food deserts on the body mass index of elementary school children. American Journal of Agricultural Economics 98(1):1-18.

Thorpe, K., Philyaw, M. 2012. The medicalization of chronic disease and costs, Annual Review of Public Health 33: 409-423.

United States Department of Justice (USDOJ). 2010. Horizontal Merger Guidelines. Published by US Department of Justice and the Federal Trade Commission, Washington DC, USA.

World Bank. 2017. Hospital Beds (per 1,000 people). Accessed April 2, 2017at http://data.worldbank.org/indicator/SH.MED.BEDS.ZS?end=2005\&start=1970

Wu, T., Majeed, A., Kuo, K. 2010. An overview of the healthcare system in Taiwan. London Journal of Primary Care 3(2): 115-119. 
Table 1. Sample statistics for key variables.

\begin{tabular}{|c|c|c|c|c|c|c|c|c|c|}
\hline \multirow[b]{3}{*}{ Year } & \multicolumn{2}{|c|}{$\begin{array}{l}\text { Township-level data of convenience stores } \\
\text { (325 townships in total) }\end{array}$} & \multicolumn{7}{|c|}{$\begin{array}{l}\text { Individual-level data on NHI insurants } \\
(9,353,987 \text { insurant-year observations) }\end{array}$} \\
\hline & \multirow{2}{*}{$\begin{array}{l}\text { HHI index } \\
(0-10,000)\end{array}$} & \multirow{2}{*}{$\begin{array}{c}\text { Store density } \\
\text { (No. of stores per } 1,000 \\
\text { capita) }\end{array}$} & \multirow[b]{2}{*}{$\mathrm{N}$} & \multicolumn{2}{|c|}{ Outpatient services } & \multicolumn{2}{|c|}{ Inpatient services } & \multicolumn{2}{|c|}{ Prescription drugs } \\
\hline & & & & $\begin{array}{l}\text { Use } \\
(0 / 1)\end{array}$ & $\begin{array}{l}\text { Expenditure } \\
(\mathrm{NT} \$ 10,000)\end{array}$ & Use $(0 / 1)$ & $\begin{array}{l}\text { Expenditure } \\
\text { (NT\$ 10,000) }\end{array}$ & $\begin{array}{l}\text { Use } \\
(0 / 1)\end{array}$ & $\begin{array}{l}\text { Expenditure } \\
\text { (NT\$ 10,000) }\end{array}$ \\
\hline 2002 & 6,940 & 0.237 & 842,917 & 0.920 & 1.174 & 0.079 & 4.575 & 0.874 & 0.349 \\
\hline 2003 & 6,648 & 0.263 & 846,477 & 0.922 & 1.228 & 0.072 & 5.332 & 0.854 & 0.376 \\
\hline 2004 & 6,356 & 0.258 & 848,577 & 0.932 & 1.391 & 0.078 & 6.754 & 0.857 & 0.438 \\
\hline 2005 & 6,287 & 0.285 & 850,969 & 0.934 & 1.430 & 0.081 & 8.552 & 0.848 & 0.445 \\
\hline 2006 & 6,171 & 0.314 & 851,945 & 0.914 & 1.475 & 0.078 & 8.869 & 0.826 & 0.471 \\
\hline 2007 & 6,060 & 0.336 & 852,112 & 0.906 & 1.534 & 0.078 & 9.224 & 0.824 & 0.484 \\
\hline 2008 & 5,906 & 0.350 & 852,112 & 0.898 & 1.604 & 0.077 & 9.656 & 0.816 & 0.520 \\
\hline 2009 & 5,814 & 0.349 & 852,112 & 0.897 & 1.673 & 0.079 & 9.569 & 0.820 & 0.537 \\
\hline 2010 & 5,820 & 0.359 & 852,196 & 0.892 & 1.711 & 0.077 & 9.968 & 0.816 & 0.540 \\
\hline 2011 & 5,686 & 0.351 & 852,285 & 0.892 & 1.796 & 0.079 & 10.156 & 0.820 & 0.578 \\
\hline 2012 & 5,567 & 0.371 & 852,285 & 0.887 & 1.853 & 0.081 & 10.082 & 0.812 & 0.576 \\
\hline
\end{tabular}

Notes: Average medical care expenditures are calculated using the sample with use. 
Table 2. Sample statistics for variables in NHI medical expenditure models.

\begin{tabular}{|c|c|c|c|}
\hline Variable & Definition & Mean & S.D. \\
\hline \multicolumn{4}{|c|}{ Individual insurant characteristics } \\
\hline Age & Age of insurant (years). & 39.891 & 20.608 \\
\hline Male & Male insurant (0/1). & 0.469 & 0.499 \\
\hline Income & Earned income of insurant (NT\$ 10,000). & 1.640 & 2.038 \\
\hline Labor insurance & Enrolled in NHI Labor Insurance program (0/1). & 0.496 & 0.500 \\
\hline $\begin{array}{l}\text { Government } \\
\text { insurance }\end{array}$ & $\begin{array}{l}\text { Enrolled in NHI Government Employee Insurance } \\
\text { program }(0 / 1) .\end{array}$ & 0.046 & 0.209 \\
\hline Farmer insurance & Enrolled in NHI Farmer Health Insurance program (0/1). & 0.116 & 0.320 \\
\hline Other insurance & Enrolled in NHI other social insurance program (0/1). & 0.342 & 0.280 \\
\hline \multicolumn{4}{|c|}{ Township characteristics } \\
\hline Medical institution & No. of hospitals and clinics per 1,000 capita. & 0.932 & 0.673 \\
\hline Bed & No. of hospital beds per 1,000 capita. & 7.523 & 7.563 \\
\hline Medical personnel & No. of medical personnel per 1,000 capita. & 0.677 & 0.402 \\
\hline Population & Population (in 100,000s). & 1.747 & 1.283 \\
\hline HHI & Herfindahl-Hirschman index (normalized to 0 - 1). & 0.501 & 0.152 \\
\hline Store density & No. of convenience stores per 1,000 capita. & 0.773 & 0.668 \\
\hline \multicolumn{4}{|l|}{ County characteristics } \\
\hline Air quality & Atmospheric particulate matter (1,000 microgram/m³). & 7.470 & 2.959 \\
\hline Garbage & Daily garbage (in $10 \mathrm{~kg}$ ) per capita. & 5.337 & 2.033 \\
\hline Dust & Monthly falling dust (in 100 tons) per km². & 4.851 & 3.254 \\
\hline Car density & No. of cars (in 100s) per km². & 8.065 & 9.371 \\
\hline Motorcycle density & No. of motorcycles (in $1,000 \mathrm{~s}$ ) per km². & 1.380 & 1.332 \\
\hline \multicolumn{4}{|l|}{ Survey year } \\
\hline Year 2002 & & 0.090 & 0.286 \\
\hline Year 2003 & & 0.090 & 0.287 \\
\hline Year 2004 & & 0.091 & 0.287 \\
\hline Year 2005 & & 0.091 & 0.288 \\
\hline Year 2006 & & 0.091 & 0.288 \\
\hline Year 2007 & & 0.091 & 0.288 \\
\hline Year 2008 & & 0.091 & 0.288 \\
\hline Year 2009 & & 0.091 & 0.288 \\
\hline Year 2010 & & 0.091 & 0.288 \\
\hline Year 2011 & & 0.091 & 0.288 \\
\hline Year 2012 & & 0.091 & 0.288 \\
\hline No. of townships & & 32 & 25 \\
\hline $\mathrm{N}^{*} \mathrm{~T}$ & & 9,353 & 3,987 \\
\hline
\end{tabular}


Table 3. Marginal effect estimates for healthcare utilization models.

\begin{tabular}{|c|c|c|c|c|c|c|c|c|c|c|c|c|}
\hline \multirow[b]{4}{*}{ Variable } & \multicolumn{4}{|c|}{ Outpatient services } & \multicolumn{4}{|c|}{ Inpatient services } & \multicolumn{4}{|c|}{ Prescription drugs } \\
\hline & \multicolumn{2}{|c|}{ Use } & \multicolumn{2}{|c|}{ Expenditure } & \multicolumn{2}{|c|}{ Use } & \multicolumn{2}{|c|}{ Expenditure } & \multicolumn{2}{|c|}{ Use } & \multicolumn{2}{|c|}{ Expenditure } \\
\hline & \multicolumn{12}{|c|}{ Full Sample } \\
\hline & Coeff. & $\%$ & Mar. Eff. & $\%$ & Coeff. & $\%$ & Mar. Eff. & $\%$ & Coeff. & $\%$ & Mar. Eff. & $\%$ \\
\hline HHI & $0.020 * * *$ & $2.21 \%$ & $200.24 * *$ & $3.11 \%$ & 0.002 & $2.16 \%$ & 102.09 & $0.28 \%$ & $0.032 * * *$ & $3.83 \%$ & $34.91 * *$ & $3.59 \%$ \\
\hline Store density & $-0.001 *$ & $-0.14 \%$ & $-66.18 *$ & $-1.03 \%$ & -0.001 & $-0.08 \%$ & -49.96 & $-0.14 \%$ & -0.003 & $-0.28 \%$ & $-2.66 *$ & $-0.27 \%$ \\
\hline$R^{2}$ & \multicolumn{2}{|c|}{0.021} & \multicolumn{2}{|c|}{0.127} & \multicolumn{2}{|c|}{0.021} & \multicolumn{2}{|c|}{0.111} & \multicolumn{2}{|c|}{0.006} & \multicolumn{2}{|c|}{0.192} \\
\hline \multirow[t]{2}{*}{$\mathrm{N} * \mathrm{~T}$} & \multicolumn{2}{|c|}{$9,353,987$} & \multicolumn{2}{|c|}{$8,498,051$} & \multicolumn{2}{|c|}{$9,353,987$} & \multicolumn{2}{|c|}{731,352} & \multicolumn{2}{|c|}{$9,353,987$} & \multicolumn{2}{|c|}{ 7,793,687 } \\
\hline & \multicolumn{12}{|c|}{ Urban Sample } \\
\hline HHI & $0.021 * * *$ & $2.26 \%$ & $189.63 * *$ & $2.98 \%$ & -0.001 & $-0.95 \%$ & 36.43 & $0.10 \%$ & $0.024 * *$ & $2.84 \%$ & $30.97 * *$ & $3.27 \%$ \\
\hline Store density & -0.006 & $-0.62 \%$ & $-159.49 * * *$ & $-2.50 \%$ & -0.001 & $-1.19 \%$ & -15.04 & $-0.04 \%$ & $-0.019 * *$ & $-2.23 \%$ & $-22.74 *$ & $-2.40 \%$ \\
\hline$R^{2}$ & \multicolumn{2}{|c|}{0.026} & \multicolumn{2}{|c|}{0.117} & \multicolumn{2}{|c|}{0.017} & \multicolumn{2}{|c|}{0.122} & \multicolumn{2}{|c|}{0.011} & \multicolumn{2}{|c|}{0.184} \\
\hline \multirow[t]{2}{*}{$\mathrm{N} * \mathrm{~T}$} & \multicolumn{2}{|c|}{$7,574,939$} & \multicolumn{2}{|c|}{$6,900,870$} & 7,574 & 939 & 559 & & $7,574, \mathrm{c}$ & & 6,325 & 934 \\
\hline & & & & & & Rural S & mple & & & & & \\
\hline HHI & $0.029 * * *$ & $3.21 \%$ & $261.77 *$ & $3.91 \%$ & 0.003 & $3.20 \%$ & 145.03 & $0.38 \%$ & 0.024 * & $2.89 \%$ & $40.95 *$ & $3.73 \%$ \\
\hline Store density & $-0.016 *$ & $-1.81 \%$ & $-225.34 * * *$ & $-3.36 \%$ & 0.002 & $2.24 \%$ & 126.93 & $0.34 \%$ & $-0.014 * *$ & $-1.76 \%$ & -29.86 & $-2.72 \%$ \\
\hline$R^{2}$ & 0.03 & & 0.14 & & 0.03 & & 0.1 & & 0.02 & & 0.21 & \\
\hline $\mathrm{N}^{*} \mathrm{~T}$ & $1,779,0$ & & $1,597,1$ & & 1,779 & 048 & 171 & & 1,779, & & 1,467,' & 753 \\
\hline
\end{tabular}

Notes: Standard errors are cluster-corrected at the township-level. The unconditional marginal effects for medical expenditures are reported. All models include township fixed effects, township-specific linear time trends, and the set of control variables reported in Table 2. ***, **, * indicate statistical significance at the $1 \%$, $5 \%$ and $10 \%$ level. 
Table 4. Marginal effect estimates for healthcare utilization models by age group.

\begin{tabular}{|c|c|c|c|c|c|c|c|c|c|c|c|c|}
\hline \multirow[b]{4}{*}{ Variable } & \multicolumn{12}{|c|}{ Child Sample (age < 18) } \\
\hline & \multicolumn{4}{|c|}{ Outpatient services } & \multicolumn{4}{|c|}{ Inpatient services } & \multicolumn{4}{|c|}{ Prescription drugs } \\
\hline & \multicolumn{2}{|c|}{ Use } & \multicolumn{2}{|c|}{ Expenditure } & \multicolumn{2}{|c|}{ Use } & \multicolumn{2}{|c|}{ Expenditure } & \multicolumn{2}{|c|}{ Use } & \multicolumn{2}{|c|}{ Expendituree } \\
\hline & Coeff. & $\%$ & Mar. Eff. & $\%$ & Coeff. & $\%$ & Mar. Eff. & $\%$ & Coeff. & $\%$ & Mar. Eff. & $\%$ \\
\hline HHI & $0.009 * *$ & $0.89 \%$ & 42.81 & $0.98 \%$ & 0.000 & $0.89 \%$ & 34.54 & $0.24 \%$ & $0.042 *$ & $4.85 \%$ & $11.29 *$ & $2.16 \%$ \\
\hline Store density & -0.001 & $-0.11 \%$ & -53.18 & $-1.22 \%$ & 0.000 & $1.11 \%$ & -6.01 & $-0.04 \%$ & -0.007 & $-0.78 \%$ & 4.22 & $0.81 \%$ \\
\hline$R^{2}$ & \multicolumn{2}{|c|}{0.049} & \multicolumn{2}{|c|}{0.090} & \multicolumn{2}{|c|}{0.017} & \multicolumn{2}{|c|}{0.019} & \multicolumn{2}{|c|}{0.016} & \multicolumn{2}{|c|}{0.047} \\
\hline \multirow[t]{2}{*}{$\mathrm{N} * \mathrm{~T}$} & \multicolumn{2}{|c|}{$1,628,452$} & \multicolumn{2}{|c|}{$1,555,979$} & \multicolumn{2}{|c|}{$1,628,452$} & \multicolumn{2}{|c|}{60,948} & \multicolumn{2}{|c|}{$1,628,452$} & \multicolumn{2}{|c|}{$1,412,599$} \\
\hline & \multicolumn{12}{|c|}{ Adult Sample (age 18-64) } \\
\hline HHI & $0.020 * * *$ & $2.17 \%$ & $172.98 * *=$ & $2.93 \%$ & 0.000 & $-0.06 \%$ & 49.80 & $0.15 \%$ & $0.030 * *$ & $3.63 \%$ & $26.88 *$ & $3.21 \%$ \\
\hline Store density & $-0.002 * *$ & $-0.20 \%$ & $-40.02 *$ & $-0.68 \%$ & 0.001 & $1.69 \%$ & 45.87 & $0.14 \%$ & $-0.009 *$ & $-1.07 \%$ & -7.86 & $-0.94 \%$ \\
\hline$R^{2}$ & \multicolumn{2}{|c|}{0.0353} & \multicolumn{2}{|c|}{0.0712} & \multicolumn{2}{|c|}{0.02} & \multicolumn{2}{|c|}{0.0636} & \multicolumn{2}{|c|}{0.0234} & \multicolumn{2}{|c|}{0.1} \\
\hline \multirow[t]{2}{*}{$\mathrm{N} * \mathrm{~T}$} & \multicolumn{2}{|c|}{$6,475,772$} & \multicolumn{2}{|c|}{$5,853,016$} & 6,475 & ,772 & 443 & 985 & 6,475 & 772 & 5,334, & 654 \\
\hline & & & & & Elderl & Sample & (age $\geq 65)$ & & & & & \\
\hline HHI & 0.007 & $0.84 \%$ & 616.06 & $3.36 \%$ & -0.002 & $-1.19 \%$ & 49.62 & $0.09 \%$ & $0.011 *$ & $1.36 \%$ & $116.59 *$ & $2.30 \%$ \\
\hline Store density & $-0.004 *$ & $-0.47 \%$ & -145.54 & $-0.79 \%$ & 0.000 & $0.19 \%$ & 50.14 & $0.09 \%$ & $-0.003 *$ & $-0.40 \%$ & 9.00 & $0.18 \%$ \\
\hline$R^{2}$ & 0.081 & & 0.02 & & 0.0 & & 0.0 & & 0.0 & & 0.04 & \\
\hline $\mathrm{N} * \mathrm{~T}$ & $1,249,7$ & & 1,058 & & 1,249 & ,763 & 223 & 008 & 1,249 & 763 & 1,019, & 551 \\
\hline
\end{tabular}

Notes: Standard errors are cluster-corrected at the township-level. The unconditional marginal effects for medical expenditures are reported. All models include township fixed effects, township-specific linear time trends, and the set of control variables reported in Table $2 .{ }^{* *}, * *, *$ indicate statistical significance at the $1 \%$, $5 \%$ and $10 \%$ level. 
Table 5. Sensitivity of estimates from healthcare utilization models to specification.

\begin{tabular}{|c|c|c|c|c|c|c|c|c|c|c|c|c|c|c|c|c|}
\hline \multirow[b]{4}{*}{ Variable } & \multicolumn{16}{|c|}{ Outpatient services } \\
\hline & \multicolumn{4}{|c|}{ Model A } & \multicolumn{4}{|c|}{ Model B } & \multicolumn{4}{|c|}{ Model C } & \multicolumn{4}{|c|}{ Model D } \\
\hline & \multicolumn{2}{|l|}{ Use } & \multicolumn{2}{|c|}{ Expenditure } & \multicolumn{2}{|l|}{ Use } & \multicolumn{2}{|c|}{ Expenditure } & \multicolumn{2}{|l|}{ Use } & \multicolumn{2}{|c|}{ Expenditure } & \multicolumn{2}{|l|}{ Use } & \multicolumn{2}{|c|}{ Expenditure } \\
\hline & Coeff. & S.E. & Coeff. & S.E. & Coeff. & S.E. & Coeff. & S.E. & Coeff. & S.E. & Coeff. & S.E. & Coeff. & S.E. & Coeff. & S.E. \\
\hline HHI & 0.000 & 0.005 & 0.046 & 0.034 & $0.023 * * *$ & 0.003 & $0.009 * *$ & 0.004 & $0.020 * * *$ & 0.004 & $0.012 * *$ & 0.005 & $0.021 * * *$ & 0.004 & $0.013 * *$ & 0.005 \\
\hline Store density & $-0.013 * *$ & 0.005 & $-0.086 * *$ & 0.034 & $-0.003 * * *$ & 0.001 & $-0.007 * *$ & 0.004 & $-0.001 *$ & 0.001 & $-0.010 *$ & 0.006 & $-0.001 *$ & 0.001 & $-0.009 *$ & 0.005 \\
\hline Other controls & Yes & & Yes & & Yes & & Yes & & Yes & & Yes & & Yes & & Yes & \\
\hline Year fixed effects & Yes & & Yes & & Yes & & Yes & & Yes & & Yes & & Yes & & Yes & \\
\hline Township FE & No & & No & & Yes & & Yes & & Yes & & Yes & & Yes & & Yes & \\
\hline Township*time & No & & No & & No & & No & & Yes & & Yes & & No & & No & \\
\hline Township*time ${ }^{2}$ & No & & No & & No & & No & & No & & No & & Yes & & Yes & \\
\hline$R^{2}$ & 0.015 & & 0.121 & & 0.018 & & 0.125 & & 0.021 & & 0.127 & & 0.022 & & 0.127 & \\
\hline \multirow[t]{2}{*}{$\mathrm{N}^{*} \mathrm{~T}$} & \multicolumn{2}{|c|}{$9,353,987$} & \multicolumn{2}{|c|}{$8,498,051$} & \multicolumn{2}{|c|}{ 9,353,987 } & \multicolumn{2}{|c|}{$8,498,051$} & \multicolumn{2}{|c|}{$9,353,987$} & \multicolumn{2}{|c|}{$8,498,051$} & \multicolumn{2}{|c|}{$9,353,987$} & \multicolumn{2}{|c|}{$8,498,051$} \\
\hline & \multicolumn{16}{|c|}{ Prescription drugs } \\
\hline HHI & $0.025 * *$ & 0.012 & 0.063 & 0.043 & $0.035 * * *$ & 0.009 & $0.008 * * *$ & 0.003 & $0.032 * * *$ & 0.009 & $0.005 * *$ & 0.002 & $0.031 * * *$ & 0.008 & $0.006 * *$ & 0.003 \\
\hline Store density & 0.035 & 0.034 & $-0.146 * * *$ & 0.056 & $-0.005 *$ & 0.003 & $-0.000 *$ & 0.000 & -0.003 & 0.006 & $-0.000 *$ & 0.000 & -0.003 & 0.005 & $-0.000 *$ & 0.000 \\
\hline Other controls & \multicolumn{2}{|l|}{ Yes } & \multicolumn{2}{|l|}{ Yes } & \multicolumn{2}{|l|}{ Yes } & \multicolumn{2}{|l|}{ Yes } & \multicolumn{2}{|l|}{ Yes } & Yes & & Yes & & Yes & \\
\hline Year fixed effects & Yes & & Yes & & Yes & & Yes & & Yes & & Yes & & Yes & & Yes & \\
\hline Township FE & No & & No & & Yes & & Yes & & Yes & & Yes & & Yes & & Yes & \\
\hline Township*time & No & & No & & No & & No & & Yes & & Yes & & No & & No & \\
\hline Township*time ${ }^{2}$ & No & & No & & No & & No & & No & & No & & Yes & & Yes & \\
\hline$R^{2}$ & 0.010 & & 0.165 & & 0.013 & & 0.188 & & 0.016 & & 0.192 & & 0.017 & & 0.193 & \\
\hline $\mathrm{N} * \mathrm{~T}$ & $9,353,9$ & & $7,793,68$ & & $9,353,98$ & & $7,793,68$ & & $9,353,9$ & & $7,793,68$ & & $9,353,98$ & & $7,793,6$ & \\
\hline
\end{tabular}

Notes: Standard errors are cluster-corrected at the township-level. Other control variables are reported in Table $2 . * * *$, **, * indicate statistical significance at the $1 \%$, $5 \%$ and $10 \%$ level. 
Table 6. Marginal effect estimates for healthcare utilization models using the subsample without entry or exit of convenience store outlets.

\begin{tabular}{|c|c|c|c|c|c|c|c|c|c|c|c|}
\hline \multirow[b]{3}{*}{ Variable } & \multicolumn{4}{|c|}{ Outpatient services } & \multicolumn{4}{|c|}{ Inpatient services } & \multicolumn{3}{|c|}{ Prescription drugs } \\
\hline & \multicolumn{2}{|c|}{ Use } & \multicolumn{2}{|c|}{ Expenditure } & \multicolumn{2}{|c|}{ Use } & \multicolumn{2}{|c|}{ Expenditure } & \multicolumn{2}{|c|}{ Use } & Expenditure \\
\hline & Coeff. & $\%$ & Mar. Eff. & $\%$ & Coeff. & $\%$ & Mar. Eff. & $\%$ & Coeff. & $\%$ & Mar. Eff. \% \\
\hline HHI & $0.018 * *$ & $2.11 \%$ & $193.28 *$ & $2.58 \%$ & 0.002 & $1.76 \%$ & 199.93 & $0.43 \%$ & $0.033 *$ & $4.12 \%$ & $63.40 * 5.21 \%$ \\
\hline$R^{2}$ & \multicolumn{2}{|c|}{0.060} & \multicolumn{2}{|c|}{0.184} & \multicolumn{2}{|c|}{0.036} & \multicolumn{2}{|c|}{0.082} & \multicolumn{2}{|c|}{0.037} & 0.247 \\
\hline $\mathrm{N} * \mathrm{~T}$ & \multicolumn{2}{|c|}{147,668} & \multicolumn{2}{|c|}{128,268} & \multicolumn{2}{|c|}{147,668} & \multicolumn{2}{|c|}{15,019} & \multicolumn{2}{|c|}{147,668} & 117,746 \\
\hline
\end{tabular}

Notes: The sample include 61 townships in 2008-2011with the same convenience stores in each year. Standard errors are cluster-corrected at the township-level. The unconditional marginal effects for medical expenditures are reported. All models include township fixed effects, township-specific linear time trends, and the set of control variables reported in Table 2. ***, **, * indicate statistical significance at the $1 \%, 5 \%$ and $10 \%$ level. 
Table 7. Marginal effect estimates for healthcare utilization models by for selected NHI medical departments.

\begin{tabular}{|c|c|c|c|c|c|c|c|c|c|c|c|c|c|c|c|c|}
\hline \multicolumn{17}{|c|}{ Outpatient services } \\
\hline \multirow[b]{3}{*}{ Variable } & \multicolumn{4}{|c|}{ Digestive gastroenterology } & \multicolumn{4}{|c|}{ Orthopedics } & \multicolumn{4}{|c|}{ Cardiology } & \multicolumn{4}{|c|}{ General surgery } \\
\hline & \multicolumn{2}{|c|}{ Use } & \multicolumn{2}{|c|}{ Expenditure } & \multicolumn{2}{|c|}{ Use } & \multicolumn{2}{|c|}{ Expenditure } & \multicolumn{2}{|c|}{ Use } & \multicolumn{2}{|c|}{ Expenditure } & \multicolumn{2}{|c|}{ Use } & \multicolumn{2}{|c|}{ Expenditure } \\
\hline & Coeff. & $\%$ & Mar. Eff. & $\%$ & Coeff. & $\%$ & Mar. Eff. & $\%$ & Coeff. & $\%$ & Mar. Eff. & $\%$ & Coeff. & $\%$ & Mar. Eff. & $\%$ \\
\hline HHI & $0.003 * * *$ & $3.45 \%$ & $82.13 * *$ & $3.05 \%$ & 0.004 & $2.56 \%$ & 12.46 & $1.43 \%$ & -0.003 & $-3.61 \%$ & 19.46 & $0.14 \%$ & 0.003 & $2.52 \%$ & 9.33 & $0.34 \%$ \\
\hline Store density & -0.004 & $-5.30 \%$ & -36.08 & $-1.52 \%$ & 0.001 & $0.79 \%$ & 1.62 & $0.22 \%$ & -0.001 & $-2.08 \%$ & 50.15 & $0.39 \%$ & -0.002 & $-1.64 \%$ & -2.86 & $-0.12 \%$ \\
\hline$R^{2}$ & \multicolumn{2}{|c|}{0.032} & \multicolumn{2}{|c|}{0.091} & \multicolumn{2}{|c|}{0.032} & \multicolumn{2}{|c|}{0.089} & \multicolumn{2}{|c|}{0.082} & \multicolumn{2}{|c|}{0.077} & \multicolumn{2}{|c|}{0.015} & \multicolumn{2}{|c|}{0.023} \\
\hline $\mathrm{N}^{*} \mathrm{~T}$ & \multicolumn{2}{|c|}{$9,353,987$} & \multicolumn{2}{|c|}{769,090} & \multicolumn{2}{|c|}{$9,353,987$} & \multicolumn{2}{|c|}{$1,325,666$} & \multicolumn{2}{|c|}{ 9,353,987 } & \multicolumn{2}{|c|}{661,855} & \multicolumn{2}{|c|}{ 9,353,987 } & \multicolumn{2}{|c|}{$1,249,973$} \\
\hline \multicolumn{17}{|c|}{ Prescription drugs } \\
\hline $\mathrm{HHI}$ & $0.003 * *$ & $4.42 \%$ & $24.92 *$ & $3.63 \%$ & 0.003 & $2.59 \%$ & -18.62 & $-0.98 \%$ & -0.001 & $-2.20 \%$ & 10.14 & $0.12 \%$ & 0.005 & $4.04 \%$ & -0.30 & $-0.02 \%$ \\
\hline Store density & -0.004 & $-5.82 \%$ & -8.12 & $-1.22 \%$ & -0.005 & $-3.88 \%$ & 0.67 & $0.08 \%$ & -0.001 & $-1.87 \%$ & 39.53 & $0.43 \%$ & 0.002 & $1.33 \%$ & 0.26 & $0.02 \%$ \\
\hline$R^{2}$ & \multicolumn{2}{|c|}{0.029} & \multicolumn{2}{|c|}{0.121} & \multicolumn{2}{|c|}{0.029} & 0.07 & & 0.0 & & 0.12 & & 0.0 & & 0.07 & \\
\hline $\mathrm{N}^{*} \mathrm{~T}$ & $9,353, \subseteq$ & 987 & 595,7 & 765 & 9,353 & ,987 & 1,095, & 696 & 9,353 & 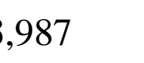 & 579,7 & 703 & 9,353 & 987 & 930,78 & 80 \\
\hline
\end{tabular}

Notes: Standard errors are cluster-corrected at the township-level. The unconditional marginal effects for medical expenditures are reported. All models include township fixed effects, township-specific linear time trends, and the set of control variables reported in Table $2 . * * *$, **, * indicate statistical significance at the $1 \%$, $5 \%$ and $10 \%$ level. 
Table 8. Sample statistics for variables in NHIS models.

\begin{tabular}{|c|c|c|c|}
\hline Variable & Definition & Mean & S.D. \\
\hline \multicolumn{4}{|l|}{ Dependent variables } \\
\hline Fruits/vegetables & Frequency of fruit or vegetable consumption (0-4). & 3.543 & 0.682 \\
\hline Less sugary drinks & Frequency of yogurt, milk or soymilk consumption (0-4). & 1.834 & 0.826 \\
\hline Sugary drinks & Frequency of sugar-sweetened drink consumption (0-4). & 1.356 & 1.202 \\
\hline Fast food & Frequency of hamburger, pizza or fries consumption (0-4). & 1.940 & 1.719 \\
\hline Proteins & $\begin{array}{l}\text { Frequency of meat, poultry, fish and other seafood, egg or soy product } \\
\text { consumption (0-4). }\end{array}$ & 2.627 & 0.718 \\
\hline Rice/noodles & Frequency of rice or noodle consumption (0-4). & 3.925 & 0.357 \\
\hline Sweets & $\begin{array}{l}\text { Frequency of cookie, chocolate, cake, bread or ice cream } \\
\text { consumption (0-4). }\end{array}$ & 1.482 & 0.763 \\
\hline Coffee/tea & Average frequency of coffee or tea consumption (0-4). & 1.556 & 1.137 \\
\hline Obese & Obese weight status (If BMI $>=27$ then obese=1). & 0.148 & 0.355 \\
\hline BMI & Body Mass Index (weight/height²). & 22.350 & 4.327 \\
\hline \multicolumn{4}{|l|}{ Explanatory variables } \\
\hline Store density & No. of convenience stores per 1,000 capita in each township. & 0.416 & 0.239 \\
\hline HHI & Herfindahl-Hirschman index in each township (normalized to $0-1$ ). & 0.491 & 0.156 \\
\hline Age & Age of the respondent (in year). & 35.338 & 19.781 \\
\hline Male & Male gender $(0 / 1)$. & 0.510 & 0.500 \\
\hline Primary & Finished elementary school or lower education (0/1). & 0.310 & 0.462 \\
\hline Junior high & Finished junior high school (0/1). & 0.153 & 0.360 \\
\hline Senior high & Finished senior high school (0/1). & 0.268 & 0.443 \\
\hline College & College education (0/1). & 0.234 & 0.423 \\
\hline Graduate & Attended graduate school or higher education (0/1). & 0.028 & 0.164 \\
\hline Income & Family income (NT\$ 10,000). & 6.370 & 4.455 \\
\hline Employment & Currently employed (0/1). & 0.513 & 0.500 \\
\hline HH size & No. of people living in the household. & 4.782 & 11.912 \\
\hline Area & Township area (in $100 \mathrm{~km}^{2}$ ). & 0.441 & 0.677 \\
\hline Population & Township population (in 100,000s). & 1.754 & 1.221 \\
\hline Medical institution & No. of hospital and clinics per 1,000 capita in each township. & 0.861 & 0.599 \\
\hline Beds & No. of beds per 1,000 capita in each township. & 6.439 & 6.799 \\
\hline Medical personnel & No. of physicians per 1,000 capita in each township. & 0.625 & 0.350 \\
\hline $\mathrm{N}$ & & 22, & 423 \\
\hline
\end{tabular}


Table 9. Marginal effect estimates for NHIST obesity and BMI Z-score models.

\begin{tabular}{|c|c|c|c|c|c|c|c|c|c|}
\hline \multirow{3}{*}{$\begin{array}{l}\text { Dependent } \\
\text { Variable } \\
\text { Variable }\end{array}$} & \multicolumn{6}{|c|}{ Obesity } & \multicolumn{3}{|c|}{ BMI Z-score } \\
\hline & \multicolumn{2}{|c|}{ Full sample } & \multicolumn{2}{|c|}{ Urban sample } & \multicolumn{2}{|c|}{ Rural sample } & \multirow{2}{*}{$\begin{array}{c}\text { Full sample } \\
\text { Coeff. }\end{array}$} & \multirow{2}{*}{$\begin{array}{c}\text { Urban sample } \\
\text { Coeff. }\end{array}$} & \multirow{2}{*}{$\begin{array}{c}\text { Rural sample } \\
\text { Coeff. }\end{array}$} \\
\hline & Coeff. & $\%$ & Coeff. & $\%$ & Coeff. & $\%$ & & & \\
\hline HHI & $0.034 * * *$ & $23.2 \%$ & $0.021 *$ & $14.5 \%$ & $0.056 * * *$ & $34.1 \%$ & $0.137 * *$ & 0.138 & $0.203 * * *$ \\
\hline Store density & $-0.015 *$ & $-10.2 \%$ & -0.024 & $-16.3 \%$ & $-0.028 * * *$ & $-17.1 \%$ & $-0.081 *$ & -0.110 & $-0.109 *$ \\
\hline$R^{2}$ & \multicolumn{2}{|c|}{0.027} & \multicolumn{2}{|c|}{0.026} & \multicolumn{2}{|c|}{0.034} & 0.291 & 0.309 & 0.146 \\
\hline \multirow[t]{2}{*}{$\mathrm{N}$} & \multicolumn{2}{|c|}{22,423} & \multicolumn{2}{|c|}{17,606} & \multicolumn{2}{|c|}{4,817} & 22,423 & 17,606 & 4,817 \\
\hline & \multicolumn{2}{|c|}{$\begin{array}{l}\text { Children } \\
\text { (age < 18) }\end{array}$} & \multicolumn{2}{|c|}{$\begin{array}{c}\text { Adult } \\
\text { (age 18-64) }\end{array}$} & \multicolumn{2}{|c|}{$\begin{array}{c}\text { Elderly } \\
\text { (age } \geq 65 \text { ) }\end{array}$} & $\begin{array}{l}\text { Children } \\
\text { (age < 18) }\end{array}$ & $\begin{array}{c}\text { Adult } \\
\text { (age 18-64) }\end{array}$ & $\begin{array}{c}\text { Elderly } \\
\text { (age } \geq 65)\end{array}$ \\
\hline Variable & Coeff. & $\%$ & Coeff. & $\%$ & Coeff. & $\%$ & Coeff. & Coeff. & Coeff. \\
\hline HHI & -0.020 & $.3 \%$ & $0.036 * * *$ & $22.9 \%$ & 0.002 & $1.0 \%$ & -0.009 & $0.143 * *$ & * $\quad 0.211$ \\
\hline Store density & $-0.006 \quad-6$ & $2 \%$ & -0.007 & $-4.3 \%$ & -0.017 & $-8.4 \%$ & -0.174 & -0.003 & -0.337 \\
\hline$R^{2}$ & \multicolumn{2}{|c|}{0.017} & \multicolumn{2}{|c|}{0.033} & \multicolumn{2}{|l|}{0.035} & 0.217 & 0.127 & 0.049 \\
\hline $\mathrm{N}$ & \multicolumn{2}{|c|}{5,266} & \multicolumn{2}{|c|}{14,801} & 2,356 & & 5,266 & 14,801 & 2,356 \\
\hline
\end{tabular}

Notes: NHIST sampling weights are used in estimation and standard errors are cluster-corrected at the county-level. ***, **, * indicate statistical significance at the $1 \%, 5 \%$ and $10 \%$ level. 
Table 10. Marginal effect estimates for NHIST food consumption frequency models.

\begin{tabular}{|c|c|c|c|c|c|c|c|c|c|c|c|c|c|c|c|c|}
\hline \multirow{2}{*}{ Variable } & \multicolumn{16}{|c|}{ Full sample $(\mathrm{N}=22,423)$} \\
\hline & \multicolumn{2}{|c|}{ Fruits/vegetables } & \multicolumn{2}{|c|}{$\begin{array}{c}\text { Less sugary } \\
\text { drinks }\end{array}$} & \multicolumn{2}{|c|}{ Proteins } & \multicolumn{2}{|c|}{ Sugary drinks } & \multicolumn{2}{|c|}{ Fast Food } & \multicolumn{2}{|c|}{ Rice/noodles } & \multicolumn{2}{|c|}{ Sweets } & \multicolumn{2}{|c|}{ Coffee/tea } \\
\hline HHI & $-0.083 * *$ & $-1.2 \%$ & $-0.151 * * *$ & $-2.7 \%$ & $0.061 * * *$ & $2.3 \%$ & $0.065 *$ & $4.5 \%$ & $0.117 * *$ & $6.0 \%$ & 0.012 & $0.3 \%$ & $-0.166 * * *$ & $-11.2 \%$ & $-0.228 * * *$ & $-14.7 \%$ \\
\hline $\begin{array}{l}\text { Store } \\
\text { density }\end{array}$ & $0.080 * * *$ & $1.1 \%$ & $0.069 * * *$ & $1.3 \%$ & -0.060 & $-2.3 \%$ & -0.002 & $-0.1 \%$ & $-0.105 * * *$ & $-5.4 \%$ & 0.010 & $0.3 \%$ & 0.032 & $2.2 \%$ & 0.048 & $3.1 \%$ \\
\hline$R^{2}$ & \multicolumn{16}{|c|}{ Urban sample $(\mathrm{N}=17,606)$} \\
\hline HHI & $-0.038 * *$ & $-0.5 \%$ & $-0.143 * *$ & $-2.6 \%$ & $0.088 * * *$ & $3.3 \%$ & $0.217 * * *$ & $16.1 \%$ & 0.063 & $3.1 \%$ & 0.019 & $0.5 \%$ & $-0.124 *$ & $-8.2 \%$ & $-0.158 * * *$ & $-10.2 \%$ \\
\hline $\begin{array}{l}\text { Store } \\
\text { density }\end{array}$ & $0.105 * * *$ & $1.5 \%$ & $0.091 * *$ & $1.6 \%$ & -0.080 & $-3.0 \%$ & -0.013 & $-1.0 \%$ & $-0.101 * * *$ & $-5.0 \%$ & 0.011 & $0.3 \%$ & 0.039 & $2.6 \%$ & -0.016 & $-1.0 \%$ \\
\hline$R^{2}$ & \multicolumn{2}{|l|}{0.038} & \multicolumn{2}{|c|}{0.116} & \multicolumn{2}{|c|}{0.071} & \multicolumn{2}{|c|}{0.152} & \multicolumn{2}{|c|}{0.244} & \multicolumn{2}{|c|}{0.016} & \multicolumn{2}{|l|}{0.218} & \multicolumn{2}{|l|}{0.208} \\
\hline$R^{2}$ & 0.084 & & 0.114 & & 0.057 & & 0.15 & & 0.21 & & 0.01 & & 0.144 & & 0.098 & \\
\hline
\end{tabular}

Notes: NHIST sampling weights are used in estimation and standard errors are cluster-corrected at the county-level. The set of control variables is reported in Table A2. ***,

**, * indicate statistical significance at the $1 \%, 5 \%$ and $10 \%$ level. 
Table 11. Estimation results for NHIST food consumption frequency equations by age group.

\begin{tabular}{|c|c|c|c|c|c|c|c|c|c|c|c|c|c|c|c|c|}
\hline \multirow[b]{3}{*}{ Variable } & \multicolumn{16}{|c|}{ Child sample (age < 18; N=5,266) } \\
\hline & \multicolumn{2}{|c|}{ Fruits/vegetables } & \multicolumn{2}{|c|}{$\begin{array}{c}\text { Less sugary } \\
\text { drinks }\end{array}$} & \multicolumn{2}{|c|}{ Proteins } & \multicolumn{2}{|c|}{ Sugary drinks } & \multicolumn{2}{|c|}{ Fast Food } & \multicolumn{2}{|c|}{ Rice/noodles } & \multicolumn{2}{|c|}{ Sweets } & \multicolumn{2}{|c|}{ Coffee/tea } \\
\hline & Coeff. & $\%$ & Coeff. & $\%$ & Coeff. & $\%$ & Coeff. & $\%$ & Coeff. & $\%$ & Coeff. & $\%$ & Coeff. & $\%$ & Coeff. & $\%$ \\
\hline HHI & $-0.309 * * *$ & $-8.8 \%$ & -0.155 & $-7.1 \%$ & 0.060 & $2.2 \%$ & 0.103 & $5.7 \%$ & $0.170 * *$ & $17.8 \%$ & -0.072 & $-1.8 \%$ & -0.067 & $-3.3 \%$ & 0.059 & $7.1 \%$ \\
\hline $\begin{array}{l}\text { Store } \\
\text { density }\end{array}$ & 0.000 & $-0.01 \%$ & 0.074 & $3.3 \%$ & $-0.085 *$ & $-3.1 \%$ & 0.011 & $0.6 \%$ & $-0.108 *$ & $-11.3 \%$ & 0.024 & $0.6 \%$ & $0.115 *$ & $5.6 \%$ & 0.003 & $0.4 \%$ \\
\hline$R^{2}$ & \multicolumn{2}{|c|}{0.035} & \multicolumn{2}{|c|}{0.128} & \multicolumn{2}{|l|}{0.034} & \multicolumn{2}{|c|}{0.042} & \multicolumn{2}{|l|}{0.032} & \multicolumn{2}{|c|}{0.016} & \multicolumn{2}{|l|}{0.049} & \multicolumn{2}{|l|}{0.119} \\
\hline & \multicolumn{16}{|c|}{ Adult sample (age 18-64; N=14,801) } \\
\hline HHI & $-0.023 * * *$ & $-0.7 \%$ & $-0.105 * *$ & $-6.0 \%$ & $0.043 * *$ & $1.6 \%$ & 0.017 & $1.3 \%$ & $0.100 * *$ & $16.4 \%$ & 0.021 & $0.5 \%$ & $-0.141 * *$ & $-10.4 \%$ & $-0.293 * * *$ & $-16.0 \%$ \\
\hline $\begin{array}{l}\text { Store } \\
\text { density }\end{array}$ & -0.081 & $-2.3 \%$ & -0.113 & $-6.4 \%$ & -0.048 & $-1.8 \%$ & -0.04 & $-2.8 \%$ & $-0.078 * *$ & $-12.8 \%$ & 0.007 & $0.2 \%$ & -0.006 & $-0.4 \%$ & -0.038 & $-2.1 \%$ \\
\hline \multirow[t]{2}{*}{$R^{2}$} & \multicolumn{2}{|c|}{0.085} & \multicolumn{2}{|c|}{0.082} & \multicolumn{2}{|l|}{0.048} & \multicolumn{2}{|c|}{0.151} & \multicolumn{2}{|l|}{0.195} & \multicolumn{2}{|c|}{0.017} & \multicolumn{2}{|l|}{0.077} & \multicolumn{2}{|l|}{0.050} \\
\hline & \multicolumn{16}{|c|}{ Elderly sample (age $\geq 65 ; \mathrm{N}=2,356$ ) } \\
\hline HHI & 0.565 & $16.0 \%$ & $-0.155 * *$ & $-10.4 \%$ & -0.707 & $-31.3 \%$ & -0.23 & $-34.3 \%$ & $0.118 * *$ & $57.5 \%$ & 0.370 & $9.4 \%$ & $-0.136 * *$ & $-13.1 \%$ & 0.454 & $39.1 \%$ \\
\hline $\begin{array}{l}\text { Store } \\
\text { density }\end{array}$ & -0.101 & $-2.9 \%$ & 0.032 & $2.2 \%$ & 0.527 & $23.4 \%$ & 0.086 & $12.9 \%$ & $-0.101 * * *$ & $-49.3 \%$ & 0.163 & $4.1 \%$ & $0.061 * *$ & $5.9 \%$ & 0.298 & $25.7 \%$ \\
\hline$R^{2}$ & 0.113 & & 0.101 & & 0.094 & & 0.04 & & 0.248 & & 0.06 & & 0.087 & & 0.190 & \\
\hline
\end{tabular}

Notes: NHIST sampling weights are used in estimation and standard errors are cluster-corrected at the county-level. The set of control variables is reported in Table A2. ***,

**, * indicate statistical significance at the $1 \%, 5 \%$ and $10 \%$ level. 
Figure 1. Geographic distribution of the HHI measure of inter-brand competition between convenience store chains in Taiwan.

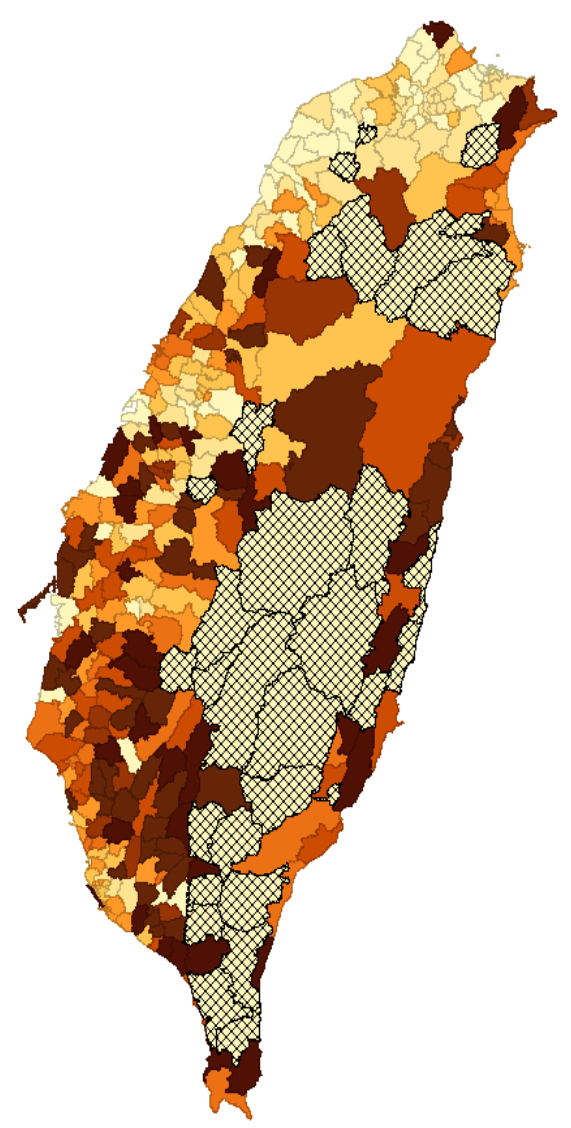

Notes: The HHI assigned to each township is the average value between 2002 and 2012. The black and white checkered areas indicate townships without any convenience store outlets. For the areas with marked colors, darker colored townships are those with a higher HHI (i.e. lower degree of inter-brand competition), while those with lighter colors have a lower HHI (i.e. high degree of inter-brand competition). 